\title{
Horizontal cooperation on investment: Evidence from mobile network sharing
}

\author{
Anca Cojoc ${ }^{1}$, Marc Ivaldi ${ }^{2}$, Frank P. Maier-Rigaud ${ }^{3}$, Oliver März ${ }^{4}$
}

April 2020

\section{PRELIMINARY DRAFT - COMMENTS WELCOME}

\begin{abstract}
We present a structural model to investigate the effects of horizontal cooperation on investment in the context of telecommunication networks. More specifically, we estimate the effect of network sharing in the mobile telecommunications industry on prices, network quality and consumer welfare. The presented framework allows estimating the effects of different types of sharing agreements including common ownership of shared assets in a joint venture company or collaboration via geographical separation (geo-split principle). The proposed identification strategy relies on differences in the costs of network deployment of shared versus non-shared network infrastructure, with different costs affecting operators' optimal choice of price and network quality. We apply the structural model to estimate the effects of a network sharing agreement in the Czech Republic, using a combination of unique datasets on prices, network quality measured as average download speed and operator's costs of network deployment. The results of our model indicate that horizontal cooperation on investments may be beneficial for consumers. Specifically, the network sharing agreement under study generated cost savings for the sharing parties, which were passed-on to consumers in the form of lower prices and higher average download speed. Our findings are of relevance to the assessment of network sharing agreements, which, considering the substantial investment cost associated with the $5 \mathrm{G}$ technology, are likely to play an even greater role in the telecommunications industry in the future. The findings are also of relevance to the general literature on horizontal cooperation on investments.
\end{abstract}

Keywords: mobile telecommunication networks, network sharing, cooperation on investment, 4G, 5G horizontal cooperation; empirical industrial organization

JEL: L40, L96, L11

\footnotetext{
${ }^{1}$ NERA Economic Consulting, London.

2 Toulouse School of Economics and NERA Economic Consulting, Paris, Brussels.

${ }^{3}$ IESEG (LEM-CNRS) and NERA Economic Consulting, Berlin, Paris, Brussels.

${ }^{4}$ NERA Economic Consulting, Berlin.

We would like to thank Philipp Heller, Dragan Jovanovic and Vicente Lagos Toro for helpful comments and suggestions. This work draws on consulting work the authors have done on behalf of a mobile network operator in response to allegations of anti-competitive behavior in the European Commission case AT. 40305. The opinions expressed reflect only the authors' views.
} 


\section{Introduction}

Over the last decade, consolidation in the telecommunication markets across Europe has been closely scrutinized by competition authorities and regulators. Faced with increasing demands for data and decreasing revenues per user both triggered by the raise of OTT services (like messaging, video and streaming apps), mobile network operators (MNOs) continue to look for ways to reduce investment costs while accelerating the deployment of their networks. In particular, MNOs have been relying on mergers, joint ventures and network sharing agreements (NSAs) as a way of reducing the costs of investment. Over the last decade there has been a substantial number of mergers in the mobile telecommunications sector in Europe alone. A great proportion of such mergers have been approved only once operators offered remedies addressing the anti-competitive effects identified by the competition authorities.

In light of this, NSAs have become attractive for operators in their efforts to save costs and achieve wider, faster and less costly network deployment. The extent of sharing, and thus the extent of cost savings, ranges from passive sharing (i.e., sharing of physical infrastructure, such as sites and masts) to active sharing (i.e., passive sharing with additional sharing of the radio access network (RAN)) to core network sharing (i.e., passive and active sharing with additional sharing of the core network). In the European Union, passive NSAs are present in all countries and active sharing is becoming more frequent as well. With the need to improve mobile networks, the new $5 \mathrm{G}$ technology, which involves increased deployment costs as it requires a higher densification of the network, is very likely to further reinforce this trend. Thus, a clearer understanding of the effects of this specific type of horizontal cooperation is needed.

Mergers are generally assessed by weighing potential anticompetitive effects from the reduction in competition with the pro-competitive efficiencies generated by the transaction. With regard to potential anticompetitive effects, merger review often focuses on the pricing implications as increased concentration in the market following the merger might result in higher prices for consumers. In contrast to mergers, NSAs are about horizontal cooperation on network investments and mainly serve the purpose of eliminating the unnecessary duplication of certain parts of the mobile networks and the associated investment costs, while pricing and other commercial decisions continue to be made independently. The competitive effects of NSAs depend on the specificities of the agreement and the wider market in which the agreement takes place. NSAs have been widely acknowledged by the European Commission (EC) and national competition authorities (NCAs) as viable alternatives to mergers and joint ventures that bring benefits to consumers. ${ }^{5}$ Recently, in the merger between INWIT and Telecom Italia and Vodafone in Italy, the EC welcomed the parties NSAs and acknowledged that the NSAs will not only lead to a faster roll out of $5 \mathrm{G}$ but they will also increase the areas over which Telecom Italia and Vodafone will continue to compete on network quality. ${ }^{6}$ At the same time, the EC

\footnotetext{
${ }^{5}$ See for instance EC Case COMP/M. 7758 Hutchison 3G Italy / Wind / JV, p. 287-302 or EC Case COMP/M. 7612 $\mathrm{H} 3 \mathrm{~g} / \mathrm{O} 2$. The Danish competition authority also approved an NSA including RAN sharing between Telia/Telenor in 2012 (see https://www.en.kfst.dk/nyheder/kfst/english/decisions/20120229-radio-access-network-sharingagreement-between-telia-denmark-and-telenor/, accessed 15. April 2020).

${ }^{6}$ See EC's press release on INWIT/Telecom Italia, Vodafone merger, available at: https://ec.europa.eu/commission/presscorner/detail/en/IP_20_414
} 
also harbors concerns as to possible anti-competitive effects of NSAs arising from cooperation in network deployment or operation. ${ }^{7}$

In this paper we set up a model aimed at capturing the interplay between the positive effects of a mobile NSA - efficiencies brought by cost reductions in deploying and operating the shared mobile network - and the potential anti-competitive effects - the potential risk of a softening of competition due to the cooperation of operators on part of the mobile network. Our structural model disentangles the demand and supply effects of the NSA and quantifies these opposing elements and their net effect on consumer welfare. Supply effects are measured as estimated cost savings resulting from the NSA. Demand effects are measured based on the effect of the NSA on prices and the quality of the mobile network. In terms of quality, the NSA allows the operators to implement a new technology (e.g., 3G, $4 \mathrm{G}$ or $5 \mathrm{G}$ ) that provides a better quality, i.e., higher download speeds and a better coverage. The model also allows us to test the hypothesis that the cooperation among operators resulting from the NSA might have a negative effect on network quality compared to network quality that would be observed in a counterfactual without NSA.

Using data on the mobile telecommunications market in the Czech Republic, we find that two NSAs between two of the main MNOs - 02 and T-Mobile Czech Republic (TMCZ) - that are organized as a geo-split agreement and covering the $2 \mathrm{G}, 3 \mathrm{G}$ and the $4 \mathrm{G}$ technologies, have a positive effect on both, operators and consumers. In particular, our model finds that costs of the operators are roughly $40 \%$ lower when the NSAs are in place compared to costs incurred if operators had to deploy the network independently. These costs savings are passed on to consumers via lower prices, with prices on average being $14 \%$ lower with the NSAs compared to the counterfactual of independent network deployment. Consumers also benefit from the NSAs by enjoying greater network quality. Compared to independent deployment, network quality measured in terms of download speed is on average $24 \%$ higher under the NSAs. Lower prices and improved quality translate into higher consumer welfare. Four years after the implementation of the NSAs, total consumer surplus over this period is $€ 1.8$ billion larger than consumer surplus under independent network deployment.

NSAs among MNOs already play an important role as a way for MNOs to reduce network deployment and operation costs. This role is likely to increase in importance with the advent of 5G, which will require much denser networks than older technologies. Our findings are thus not only of relevance for the assessment of existing NSAs but also offer important implications for the deployment of 5G. In addition, we believe that our findings are also of relevance to the general literature on horizontal cooperation among competitors.

The remainder of the article is structured as follows. Section 2 presents a discussion of related literature, while Section 3 provides relevant background information on the mobile telecommunications industry and the different types of network sharing. Section 4 describes the framework of our structural model and the mechanism to identify the effects of network sharing on MNO's costs. In Section 5, we estimate our structural model on the mobile telecommunications industry in the Czech Republic. Complementing these findings, we present reduced-form evidence on

\footnotetext{
7 This led to the opening of case AT 40305 in 2015, where the EC voiced concerns regarding possible anticompetitive effects arising from the NSA between TMCZ and $\mathrm{O} 2$ in the Czech mobile telecommunications industry. Similarly, the Hungarian competition authority is also investigating an NSA between Magyar Telekom and Telenor. See BEREC (2018) , p. 14-15.
} 
the effects of network sharing in the Czech Republic on network quality in Section 6. Section 7 discusses further robustness checks of the structural model and Section 8 concludes.

\section{Literature review}

We study the effects of network sharing by using a structural model of competition among network operators focusing on the strategic choice of network quality. To demonstrate how this approach applies in practice, it is estimated on the Czech mobile telecommunications market that saw network sharing agreements between two large mobile network operators in 2013/2014. Maier-Rigaud, Ivaldi \& Heller (2020) also provide an evaluation of the Czech NSA focusing on its price effects. They estimate both a difference-in-differences model and a structural model of price competition among network operators. In line with the results of this paper, they find that the Czech NSA resulted in lower prices and higher consumer surplus. Their paper, however, does not directly estimate the effects of the NSA on network quality.

Our paper contributes to a recent stream of research that theoretically derives the welfare effects of competition among network operators. Bourreau et al. (2018) study the effects of network sharing via co-investment agreements. Co-investment in their setup means that an entrant can ask an incumbent to share its infrastructure, by taking on half the of infrastructure investment costs after the investment plan has been announced. ${ }^{8}$ It is thus akin to a geo-split agreement in the sense that the optimal level of network quality is decided independently but the deployed network and the costs of deployment are shared with the financing partners. In line with our empirical results, they predict that coinvestment agreements stimulate infrastructure investments and enhance social welfare.

In a similar vein, Nitsche and Wiethaus (2011) compare the effects of different regulatory regimes of per-unit access pricing versus risk-sharing. Risk-sharing among network operators in their setup implies that firms jointly decide on the investment level to maximize their profits, which is comparable to the concept of a joint venture agreement in our structural model. While our empirical application finds beneficial effects of network sharing under a geo-split agreement, Nitsche and Wiethaus' (2011) theoretical model suggests that risk-sharing regimes also generate higher consumer surplus, compared to per-unit access pricing. In contrast, Krämer and Vogelsang (2016) offer an experimental study that estimates the effects of co-investment agreements in network infrastructure. ${ }^{9}$ Based on a simple network competition game between duopolistic firms, they report that co-investment may facilitate tacit collusion, resulting in higher prices and lower consumers surplus. Our empirical results, based on the effects of a real network sharing agreement, do not confirm the laboratory results of Krämer and Vogelsang (2017) but instead show that network sharing results in lower prices and higher consumer surplus.

\footnotetext{
${ }^{8}$ In reality, co-investment agreements can be undertaken by well-established operators and can also be signed $a b$ initio, that is before any investment plan is announced.

9 Co-investment in Krämer and Vogelsang (2016) is defined as co-investing in a single shared network infrastructure and subsequent competition at the retail level. As in Nitsche and Wiethaus (2011), this setup is comparable to the joint venture agreement in our structural model, described in Section 4.2.
} 
Our paper also contributes to the theoretical literature that studies the relationship between competition and investments. ${ }^{10}$ In a recent contribution, Federico et al (2017) develop a stylized model to explain the effects of a merger on the merging parties' incentives to invest in innovation. They argue that the effect depends on the interplay of an "innovation externality", that is the internalization of a reduction in expected profits that an innovation by one party causes on the other party, and "price coordination", that is the elimination of price competition between the merging firms. They argue that absent efficiencies or spillover effects a merger reduces the incentives to innovate with the main driver being the innovation externality that reduces appropriability.

Motta and Tarantino (2017) also study the effects of a merger on the incentives to invest in costreducing innovations but allow for the possibility of a partial merger that involves cooperation on the investment decision without cooperation on prices decision. They find that partial mergers in general tend to be better for consumers than full mergers. ${ }^{11}$ While our paper does not explicitly model the investment decisions of network operators, it provides empirical support that network sharing agreements, which can under some circumstances be thought of as partial mergers, are beneficial for consumers. ${ }^{12}$

\section{Mobile telecommunication infrastructure and network sharing agreements (Difference between geo-split and JV)}

A mobile network is usually divided into two parts: the local radio access network (RAN) and the core network (CN). The CN provides the functionality of services and connects to internet and telephony networks, while the RAN connects end user's mobile devices to the core network. The last interconnecting link between the RAN and the end user is wireless. Establishing such a wireless connection requires building an infrastructure of fixed-location transceivers, also called base stations

\footnotetext{
${ }^{10}$ This theoretical literature can be traced back to the seminal works by Schumpeter and Arrow who defined two opposing views. According to Schumpeter (1942), innovation leads to higher margins and thus a monopolist has more incentive to invest than a firm in a competitive market because the monopolist seeks to maintain its leading position in the market. Arrow (1962) in contrast showed that incentives to innovate can be stronger in competitive markets as firms facing competition will seek to innovation to outperform competition. A monopolist instead has lower incentives to innovate because doing so could cannibalize its own sales. See also d'Aspremont \& Jacquemin (1988) for an early contribution showing that cooperation between competitors on investments (in R\&D) can be socially beneficial.

${ }^{11}$ While both Federico et al (2017) and Motta and Tarantino (2017) have quite strong implications for the analysis of the effects of horizontal mergers on incentives to innovate, their modelling approaches have been criticized by others. Denicolo and Polo (2018), Bourreau and Jullien (2018) as well as Jullien and Lefouili (2018) argue that these economic analyses rely on restrictive assumptions and thus do not support the view that horizontal mergers always reduce incentives to invest and innovate. These authors conclude that given the uncertainty of the direction of the effect, merger control should bear in mind that depending on the facts the case the effect of the merger can go either way. This also suggests that NSAs, which lead to coordination of investment, but not pricing decisions, should be seen more positively than mergers, since there is no harmful price coordination.

${ }^{12}$ Our application to the network sharing agreement in the Czech Republic, however, should not be thought of as equivalent to a partial merger as described by Motto and Tarantino (2017) because, as we argue, network sharing agreements organized on a geo-split principle do not involve the coordination on network quality. Furthermore, investments under NSAs should in general not be thought of as cost-reducing innovations but cost reductions due to the avoidance of unnecessary network duplication.
} 
or cells, and associated antennas. The base stations itself require physical locations, such as sites, mast or building rooftops, on which they can be built. Building and operating a mobile telecommunication network thus requires large infrastructure investments.

With increased demand for data-intensive services the deployed capacity of the network could come to its limits and, once all spectrum has been deployed and other capacity-enhancing technologies have been deployed, the operators may have to increase the number of base stations, which is costly. In addition, the rollout of newer technology standards, especially 5G, further increases the need to build more base stations to ensure high data transfer rates and fast coverage throughout a country. ${ }^{13}$

To allow for cost savings in rolling out the necessary infrastructure, mobile network operators can use different forms of network sharing. Passive sharing involves the sharing of basic infrastructure, such as the space at a rooftop of a building or on a telecommunication tower, the antenna masts, power supplies and air conditioning systems. In addition to sharing of passive assets, active sharing usually involves the sharing of the RAN equipment, meaning the base stations and antennas. ${ }^{14}$ Under most types of active sharing agreements, mobile network operators share the passive and active equipment but continue to provide services using their own dedicated frequency bands (spectrum). Finally, it is possible for MNOs to integrate at an even deeper level and share their allocated spectrum in the available frequency bands, or even some elements (or all) of their individual CN.

The different forms of network sharing and the associated cost savings associated with a greater degree of sharing are illustrated in Figure 3-1. In general, a greater degree of network sharing can be expected to allow greater cost savings, both regarding the cost of building new sites (CAPEX) and in maintaining and operating existing sites (OPEX).

\footnotetext{
${ }^{13}$ In addition, with each new technology and each new spectrum being deployed, operators are required to meet certain coverage obligations within a specific timeline. Meeting the requirements of the coverage obligations thus becomes more costly under newer technology standards, which creates incentives for network operators to engage in NSAs in order to save costs.

${ }^{14}$ More specifically, active sharing means that MNOs jointly plan (coordinate) the deployment of the key components of the RAN, namely the base stations and antennas that are required to provide the wireless connection to the end users. There is, however, some uncertainty around whether antennas are to be considered as passive or active assets.
} 
Figure 3-1: Types of network sharing

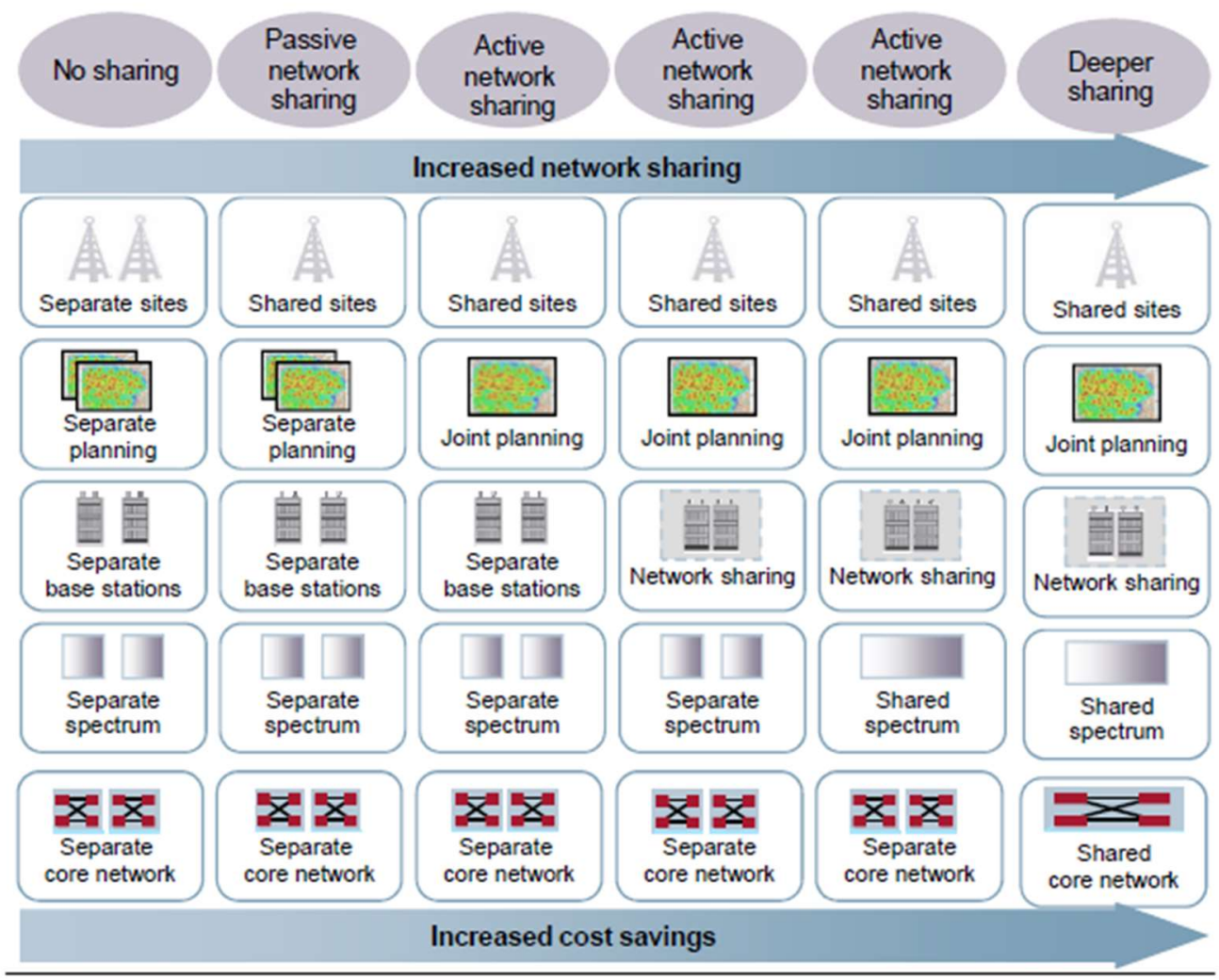

Source: Authors' illustration based on Belgian Institute for Postal services and Telecommunications.

When network operators decide to share parts of the mobile network, there are various ways to deploy and operate the network. One common practice is to form a joint venture (JV) company, which operates the parts of the shared network and provides the services to the sharing parties. Another common practice of collaboration is the geographic separation of the shared mobile network. Under this geo-split principle each operator operates the mobile network its respective area, which is its master area. In the master area, both the subscribers from the Master operator and from the other sharing operators (the Visitor operators) use the Master operator's mobile network. ${ }^{15}$ Finally, in a "salt and pepper" model, which is very similar to a geo-split ownership, the sharing parties additionally operate their own independent sites within the area of the Master operator. ${ }^{16}$ Under this type of agreement, the parties are thus sharing parts of their network but continue to operate and deploy independent sites.

Figure 3-2 depicts the different types of network sharing that vary in the degree of asset ownership of the mobile network infrastructure.

\footnotetext{
${ }^{15}$ The Misitor operators, however, keeps controls over its subscribers and services. Sharing via the geo-split principle does also not necessarily affect the independence of each party for network planning and deployment. Indeed, each operator may still be able to request from the other operator unilateral network deployment in its master area.

${ }^{16}$ Independent network deployments differ from unilateral deployments as they are done directly by the Visitor operator without involving the Master operator, while unilateral deployments are implemented by the Master operator upon request and for the benefit of the Visitor operator.
} 
Figure 3-2: Asset ownership options

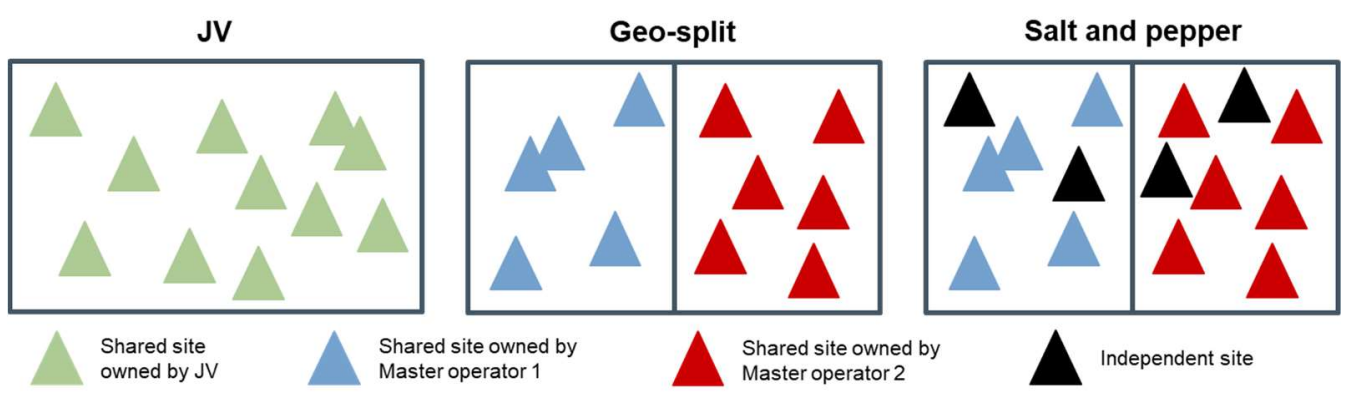

Source: Authors' illustration based on Andersen (2016).

Under a JV agreement, strategic decisions relating to investments in infrastructure and the deployment of technology are made to maximize the joint profits of all sharing parties. In contrast, under a geo-split ownership model each operator is responsible for operating the network in its master area, implying that investments into network infrastructure are governed largely independently. ${ }^{17}$ The differences in the profit-maximizing behavior of sharing firms under a JV or a geo-split agreement, respectively, are a central component of the structural model presented in Section 5 that uses different behavioral assumptions to evaluate the effects of NSAs, depending on the underlying ownership structure of the agreement.

\section{Theoretical model}

Network sharing can result in both pro-competitive and anti-competitive effects. The most direct procompetitive effect is the reduction in infrastructure expenditures: each sharing party needs to build fewer sites to provide coverage to their respective customers, which translates into lower CAPEX. In maintaining and operating a site, savings in OPEX can also be realized, for example by sharing the rental costs of a site or the costs for energy consumption. Given the overall reduced demand for sites, there may be additional indirect effects whereby in congested areas rents may be reduced to allow third party MNOs to also roll-out and operate sites more cheaply, which translates into lower CAPEX and OPEX for third parties. ${ }^{18}$ Finally, the reduced cost of building and maintaining network infrastructure does not only benefit firms but can be passed on to consumers in the form of lower prices or higher quality of service.

Network sharing also results in quality improvements through greater network coverage or through network densification. Regarding the latter point, if two MNOs share their networks, each operator will have a higher effective density of consumers by additionally serving consumers from the sharing partner. Ceteris paribus, a higher consumer density increases average download speed per consumer as consumers could be served by less distant sites. The sharing parties can thus provide higher quality at the same cost or provide the same quality at lower cost.

Network sharing agreements, however, might also be considered to have some anti-competitive effects. If both sharing parties, by the necessity to jointly plan their common infrastructure, are aware

\footnotetext{
${ }^{17}$ As explained above, geo-split agreements (and to some extent JV agreements) may have elements of unilateral deployment, whereby one operator requests investments from another operator.

${ }^{18}$ Cf. GSMA (2012).
} 
of each other's investment plans, this may increase their ability to predict and respond to the other's competitive behavior, which might facilitate tacit collusion to achieve higher prices. ${ }^{19}$ In addition, due to the joint operation of mobile infrastructure, there may be greater commonality of costs, which might further enhance their ability to collude tacitly.

A structural model can disentangle the different potential effects of the NSAs and measure the net effect on consumer welfare. It is possible to investigate different assumptions on the sharing parties strategic behavior regarding the choice of network quality. The following sub-sections explain how consumer demand for telecommunication services and firm's strategic behavior could be described in a structural modelling framework.

\subsection{Demand model}

Consumer demand is assumed to be represented by a nested logit model, following Berry (1994). ${ }^{20}$ The nested logit model groups consumers' choices into nests and creates a hierarchical structure between alternative options, with choices within nests being closer substitutes than choices across different nests. ${ }^{21}$ In a first step, consumers choose whether to use telecommunication services or not, whereby the latter case corresponds to choosing the outside option. ${ }^{22}$ When choosing to access a mobile telecommunications network, a consumer chooses the operator offering the highest relative utility compared to other options. The utility realized depends on the network quality as well as on the price to use the network. In this setup, the market share of an MNO can be interpreted as a measure of the probability that consumers choose to access a particular MNO's network. Actual market shares can be derived based on the total number of active subscribers for an operator.

The utility consumer $j$ obtains from choosing operator $i$ at time $t$ is described as follows:

$$
u_{i j t}=\beta q_{i t}-\alpha p_{i t}+x_{i t} \delta+\xi_{i t}+(1-\sigma) \varepsilon_{i j t}+\zeta_{j g t}
$$

where, $\beta q_{i t}-\alpha p_{i t}+x_{i t} \delta+\xi_{i t}$ constitutes the mean net valuation for choosing the network of operator $i$ at time $t$ that is common to all consumers. It depends on the quality of the network $q_{i t}$, price of using the network $p_{i t}$, a vector $x_{i t}$ of observed characteristics and a vector $\xi_{i t}$ of unobserved characteristics. The term $(1-\sigma) \varepsilon_{i j t}+\zeta_{j g t}$ combines the unobserved random errors and reflects individual deviations from the mean valuation. Some deviations are shared within the same nest $g$ and are represented by the error $\zeta_{j g t}$. Other deviations are specific to consumer $j$ and operator $i$ at time $t$, as represented by $\varepsilon_{i j t}$. Parameter $\sigma$ captures the correlation of consumer preferences within

\footnotetext{
19 Exchange of information could be minimized via "Chinese walls", separate teams involved in the NSAs' activities, or any retail-specific activities.

${ }^{20}$ For a textbook introduction to the nested logit model, cf. Train (2009). For an application in merger policy, cf. Ivaldi and Verboven (2005) or Gollier and Ivaldi (2009).

${ }^{21}$ Alternatively, the nested logit model can be described in terms of correlation structure between the random error term representing idiosyncratic preferences of consumers.

22 Including the "outside option" in measuring the market size allows the model to account for changes in total demand when prices change. If the market size excluded the outside option, then the model could only show consumer movements from one product to another, but not consumers exiting from the observed market or joining the market. The existence of the outside option is also a technical requirement for the nested logit model as it allows the identification of the parameters using a simple regression analysis.
} 
a nest and lies between zero and one. ${ }^{23}$ The utility of choosing the outside option is normalized to zero.

From the assumptions on the consumer's decision-making process, the utility maximizing principle, and using the expression for the mean utility in (1) the demand in terms of market shares for each operator can be expressed as: ${ }^{24}$

$$
\ln \left(\frac{s_{i t}}{s_{0 t}}\right)=\mu_{0}+\beta q_{i t}-\alpha p_{i t}+\sigma \ln \left(s_{i \mid g t}\right)+x_{i t} \delta+\xi_{i t}
$$

where, $s_{i t}$ is the market share of operator $i$ at time $t ; s_{0 t}$ is the market share of the outside option at time $t, s_{i \mid g t}$ is the market share of operator $i$ within the nest $g$ at time $t$ and $\mu_{0}$ is a constant.

To make sure that the demand function is estimated consistently, the endogeneity problem that arises from the simultaneous relationship between (unobserved) network quality, prices and market shares needs to be accounted for by using instrumental variables. ${ }^{25}$

\subsection{Supply model}

On the supply side, each MNO sets the price and the quality of its services for consumers. We consider two types of competition between sharing parties. First, MNOs could compete by simultaneously and independently setting the level of network quality and price to maximize their own profit. We consider that this situation corresponds quite well to a geo-splitting agreement in which each operator operates the mobile network in its Master area and the subscribers from both the Master and the Visitor operators use the Master operator's network. ${ }^{26}$ We label this scenario as "geo-split equilibrium". Second, the sharing parties could compete by simultaneously and independently setting prices to maximize their own profits but coordinating on network quality to maximize their joint profit. We consider that this situation corresponds quite well to a joint venture agreement with sharing parties internalizing the negative impact of increasing network quality on their sharing partners. We label this scenario as "JV equilibrium".

In reality, MNOs decide on the level of investment in the network (e.g. physical infrastructure or available spectrum) and the level of investment has an effect on network quality and the cost of

\footnotetext{
${ }^{23}$ If $\sigma=1$, there is perfect correlation of preferences for choosing operators within the same nest. In this case, in response to a price or quality change consumers never switch to operators outside the nest. As $\sigma$ decreases, the correlation of preferences for products within the same nest decreases. If $\sigma=0$, there is no correlation of preferences the model reduces to a simple logit model. Consumers are equally likely to switch to operators in a different nest as they are to switch in the same group in response to a price or quality change.

24 To express the demand for each operator in terms of market shares, this derivation assumes that $(1-\sigma) \varepsilon_{i j t}+\zeta_{j g t}$ is i.i.d and follows a type I extreme value distribution.

${ }^{25}$ As explained in more detail in the application in Section 5.3.1, different sets of instruments have been suggested in the literature to deal with the endogeneity problem, including lags of the endogenous variables (Arellano \& Bover (1995), Blundell \& Bond (1998)), characteristics of products of rival firms a.k.a BLP-type instruments (Berry, Levinsohn \& Pakes (1995)), and lags of the endogenous variables in comparable markets a.k.a Hausman-type instruments (Nevo (2000)).

${ }^{26}$ Additionally, as explained above, depending on the details of the sharing agreement, a Visitor operator may also unilaterally request additional sites to be deployed by the Master operator or independently deploy its own sites in the area of the Master operator.
} 
providing telecommunication services. ${ }^{27}$ To account for MNO's strategic behavior with respect to network quality and the potential internalization of the negative effects on sharing partners of offering higher network quality, we do not explicitly model investments but assume that MNOs can directly set the level of network quality, for example the level of download speed available to consumers. ${ }^{28}$

The operating profits of an MNO are given by:

$$
\pi_{i t}=\left(p_{i t}-c_{i t}\right) s_{i t} N_{t}-k_{i t} q_{i t}^{2}-K_{i t}
$$

where:

- $c_{i t}$ is the marginal cost of operator $i$ at time $t$ of providing access to the network (i.e. quantity costs);

- $q_{i t}$ is the level of network quality of operator $i$ at time $t$;

- $k_{i t}$ is the quality cost parameter for operator $i$ at time $t$;

- $k_{i} q_{i t}^{2}$ is the total cost for operator $i$ at time $t$, of providing quality $q_{i t} ; ;^{29}$

- $s_{i t}$ is the market share of operator $i$ at time $t$;

- $N_{t}$ is the total market size in period $t$; and

- $K_{i t}$ is the fixed costs of operator $i$ at time $t$.

All firms in the market set prices independently and simultaneously, both under the geo-split and JV equilibrium. Equilibrium prices for each MNO are derived from equation (3) by taking the first-order condition with respect to prices:

$$
\left(p_{i t}-c_{i t}\right) \frac{\partial s_{i t}}{\partial p_{i t}}+s_{i t}=0
$$

On network quality, as explained above, sharing partners could either set quality simultaneously and independently (geo-split equilibrium), or coordinate on the choice of quality (JV equilibrium). All firms outside the network sharing agreement are assumed to compete with the sharing parties by simultaneously and independently setting quality.

\footnotetext{
${ }^{27}$ As explained in Maier-Rigaud, Heller \& Ivaldi (2020), NSA's primary purpose is the reduction of costs to rollout a network. This can both allow MNOs to increase their network quality (by increasing coverage and/or capacity) and to lower their prices.

${ }^{28}$ In general, one could also think of a sequential game with MNOs competing by first setting the level of network quality and subsequently setting prices. Estimating such a sequential game might be more realistic but would computationally be very demanding. Even under a sequential model, however, parameter estimates would still be determined by trying to match the same patterns in the data. The simultaneous timing assumption has been advocated and implemented by many studies in the academic literature (e.g. Villas-Boas (2007), Fan (2013) or Crawford et al. (2018)); hence, one could expect that a simultaneous equilibrium model provides a reasonable description of reality with substantial computational benefits.

${ }^{29}$ This implies that marginal costs of operator $i$ at time $t$ of providing network quality is given by $2 k_{i} q_{i t}$. Total quality costs are assumed to be convex to account for the fact that improving network quality becomes increasingly costly at higher levels of network quality.
} 
In the geo-split equilibrium, network quality for each MNO is derived from equation (3) by taking the first-order condition with respect to quality:

$$
\left(p_{i t}-c_{i t}\right) \frac{\partial s_{i t}}{\partial q_{i t}} N_{t}-2 k_{i t} q_{i t}=0 .
$$

After some algebraic manipulations, the equilibrium level of network quality is given by:

$$
q_{i t}^{G S}=\frac{\widehat{\beta}}{2 \widehat{\alpha} k_{i t}} s_{i t} N_{t}
$$

In the JV equilibrium each sharing party maximizes:

$$
\underset{q_{i}, q_{j}}{\operatorname{Max}}\left(p_{i t}-c_{i t}\right) s_{i t} N_{t}-k_{i t} q_{i t}^{2}-K_{i t}+\left(p_{j t}-c_{j t}\right) s_{j t} N_{t}-k_{j t} q_{j t}^{2}-K_{j t}
$$

Equilibrium network quality for is derived by taking the first-order condition with respect to quality:

$$
\frac{N_{t}(1-\widehat{\sigma})}{\widehat{\alpha}}\left(\frac{\partial s_{i t}}{\partial q_{i t}} \frac{1}{\Delta_{i t}}+\frac{\partial s_{j t}}{\partial q_{i t}} \frac{1}{\Delta_{j t}}\right)-2 k_{i t} q_{i t}=0
$$

with $\Delta_{i t}$ and $\Delta_{j t}$ defined as follows:

$$
\begin{aligned}
& \Delta_{i t}=1-\hat{\sigma} s_{i t / g}-(1-\hat{\sigma}) s_{i t} \\
& \Delta_{j t}=1-\hat{\sigma} s_{j t / g}-(1-\hat{\sigma}) s_{j t} .
\end{aligned}
$$

After some algebraic manipulations, the equilibrium level of network quality for the sharing parties is given by:

$$
q_{i t}^{J V}=\frac{\widehat{\beta} N_{t}}{2 \widehat{\alpha} k_{i t}} s_{i t}\left(1-\frac{\left(\widehat{\sigma} s_{j t / g}+(1-\widehat{\sigma}) s_{j t}\right)}{\left(1-\widehat{\sigma} s_{j t / g}-(1-\widehat{\sigma}) s_{j t}\right)}\right) .
$$

The equilibrium level of network quality before the start of the NSA as well as for outsiders to the NSA is given by the expression in equation (6).

Given observed equilibrium network quality, the quality cost parameter can be recovered and is given by:

$$
k_{i t}^{G S}=\frac{\widehat{\beta}}{2 \widehat{\alpha} q_{i t}} s_{i t} N_{t},
$$

and

$$
k_{i t}^{J V}=\frac{\widehat{\beta} N_{t}}{2 \widehat{\alpha} q_{i t}} s_{i t}\left(1-\frac{\left(\widehat{\sigma} s_{j t / g}+(1-\widehat{\sigma}) s_{j t}\right)}{\left(1-\widehat{\sigma} s_{j t / g}-(1-\widehat{\sigma}) s_{j t}\right)}\right)
$$

for the geo-split and JV equilibrium, respectively.

Finally, since the market is assumed to be in equilibrium in each quarter, the prices in the dataset are assumed to correspond to a firm's profit maximizing prices. ${ }^{30}$ At the profit-maximizing price, prices and own-price demand elasticities $\eta_{i i, t}$, are related to marginal costs $c_{i t}$, via the Lerner index.

\footnotetext{
30 The market equilibrium occurs when consumers are willing to subscribe to an operator at the stated price, and firms are willing to sign up consumers at the stated price.
} 


$$
\frac{p_{i t}-c_{i t}}{p_{i t}}=\left|\frac{1}{\eta_{i i, t}}\right|
$$

The own price elasticity is calculated from the demand estimation and given by $\eta_{i i, t}=$ $-\frac{\widehat{\alpha}}{1-\hat{\sigma}} p_{i t}\left(1-\hat{\sigma} s_{i \mid g t}-(1-\hat{\sigma}) s_{i t}\right)$. This implies that marginal costs of providing access to the network can be backed out as follows:

$$
c_{i t}=p_{i t}-\frac{1-\widehat{\sigma}}{\widehat{\alpha}\left(1-\widehat{\sigma} s_{i t \mid g}-(1-\widehat{\sigma}) s_{i t}\right)}
$$

\subsection{Identification}

To evaluate the effects of an NSA, it is necessary to compare the economic environment with the NSA in place to the environment that would have resulted had the NSA not been implemented. In our model, this is achieved by comparing the costs of network deployment and operation of the sharing parties with the costs of outsiders to the sharing agreement.

As explained in Section 3, depending on the depth of network sharing, greater cost savings can be realized compared to the alternative scenario of independent network deployment. While passive sharing involves cost savings related to the sharing of site locations and masts, active sharing involves additional cost savings related to the sharing of RAN. Under network sharing it is thus expected that the cost of deploying and operating a shared network are smaller than the costs of deploying and operating a non-shared network. Following this logic, we identify the effects of an NSA by comparing the costs of deploying shared sites, which are only observed for the sharing parties to the costs of deploying non-shared sites, which are observed for the sharing parties as well as for outsiders to the sharing agreement.

Marginal costs of providing access to the network, $c_{i t}$, are estimated as follows:

$$
c_{i t}=c_{0}+\rho^{s \text { ared }} s \text { ared_sites } s_{i t}+\rho^{\text {nons } \text { ared }} \text { non }-s \text { ared_sites } s_{i t}+\theta X_{i t}+\omega_{i t} \text {, }
$$

with $s$ ared_sites $s_{i t}$ and non $-s$ ared_sites $s_{i t}$ representing the number of shared and non-shared sites of operator $i$ at time $t$ and $X_{i t}$ describing potential additional control variables affecting costs as well as firm or time-specific fixed effects.

Counterfactual costs are computed by assuming that without the NSA, all shared sites would have been deployed independently as non-shared sites. This means that the sharing parties would keep their total capacity unchanged but would deploy capacity unilaterally at a higher cost. ${ }^{31}$

Counterfactual costs for providing access to the network are then derived according to:

$$
\tilde{c}_{i t}=c_{i t}+\left(\hat{\rho}^{\text {nons ared }}-\hat{\rho}^{s \text { ared }}\right) \times s \text { ared_sites }{ }_{i t}{ }^{4 G}
$$

\footnotetext{
${ }^{31}$ Depending on the network sharing agreement, different counterfactual scenarios are conceivable. It is easily possible to amend the model to allow for the total number of sites to differ in the counterfactual. Assuming that the total number of sites is constant, however, is likely to be a conservative assumption. If the total number of sites is higher without the NSAs (only nonshared sites) than the total number of sites with the NSAs (shared and nonshared sites), because each MNO has to deploy its own mobile network, it follows that costs per MNO in the counterfactual would likely be higher, resulting in higher prices and/or lower quality.
} 
where $\tilde{c}_{i t}$ denotes the costs of providing access to the network in the counterfactual scenario. Counterfactual costs of providing network quality can be derived analogously:

$$
\tilde{k}_{i t}^{T}=k_{i t}^{T}+\left(\hat{\rho}^{\text {nons ared }}-\hat{\rho}^{\text {s ared }}\right) \times s \text { ared_sites }{ }_{i t}{ }^{4 G}
$$

with $\tilde{k}_{i t}^{T}$ denoting the quality cost parameter in the counterfactual and $T \in\{G S, J V\}$ the geo-split and JV equilibrium, respectively.

After counterfactual costs have been estimated based on the difference in shared and non-shared sites, counterfactual market shares, prices and network quality are derived by solving a system of simultaneous equations. ${ }^{32}$

With demand having a nested logit structure, the system of equations to solve for a given firm $i$ in a quarter $t$, in the counterfactual scenario when the NSA is not active is then given by:

$$
\begin{gathered}
\tilde{c}_{i t}-\tilde{p}_{i t}+\left(\frac{1-\hat{\sigma}}{\hat{\alpha}}\right)\left(\frac{1}{1-\hat{\sigma} \tilde{s}_{i \mid g t}-(1-\hat{\sigma}) \tilde{s}_{i t}}\right)=0 \\
\tilde{s}_{i \mid g t}-\frac{\exp \left(\frac{\hat{\delta}_{i t}+\hat{\beta} \tilde{q}_{i t}-\hat{\alpha} \tilde{p}_{i t}}{1-\hat{\sigma}}\right)}{\sum_{f=1}^{F} \exp \left(\frac{\hat{\delta}_{f t}+\hat{\beta} \tilde{q}_{f t}-\hat{\alpha} \tilde{p}_{f t}}{1-\hat{\sigma}}\right)}=0 \\
\tilde{s}_{i t}-\tilde{s}_{i \mid g t} \frac{\left(\sum_{f=1}^{F} \exp \left(\frac{\hat{\delta}_{f t}+\hat{\beta} \tilde{q}_{f t}-\hat{\alpha} \tilde{p}_{f t}}{1-\hat{\sigma}}\right)\right)^{1-\hat{\sigma}}}{1+\left(\sum_{f=1}^{F} \exp \left(\frac{\hat{\delta}_{f t}+\hat{\beta} \tilde{q}_{f t}-\hat{\alpha} \tilde{p}_{f t}}{1-\hat{\sigma}}\right)\right)^{1-\hat{\sigma}}=0} \\
\tilde{q}_{i t}^{T}=\left\{\frac{\hat{\beta} N_{t} \tilde{s}_{i}}{2 \hat{\alpha} \tilde{k}_{i}}, \frac{\hat{\beta} N_{t}}{2 \hat{\alpha} k_{i t}} s_{i t}\left(1-\frac{\left(\hat{\sigma} s_{j t / g}+(1-\hat{\sigma}) s_{j t}\right)}{\left(1-\hat{\sigma} s_{j t / g}-(1-\hat{\sigma}) s_{j t}\right)}\right)\right\}=0
\end{gathered}
$$

with $\tilde{q}_{i t}^{T} \in\{G S, J V\}$ denoting the geo-split and JV equilibrium, respectively, $\hat{\delta}_{i t}=\ln \left(\frac{s_{i t}}{s_{0 t}}\right)-$ $\hat{\sigma} \ln \left(s_{i \mid g t}\right)-\hat{\beta} q_{i t}+\hat{\alpha} p_{i t}$ denoting the fixed level of consumer valuation for an MNO that is not affected by the presence an NSA, and $F$ the total number of firms in the market.

After the system of equations has been solved, on can use the resulting prices and network quality to calculate consumer surplus. Total consumer surplus aggregates the net consumer valuation when each consumer chooses the option that maximizes utility. When demand is given by a nested logit model, consumer surplus in the absence of the NSA is calculated by using counterfactual prices and network quality:

$$
C S_{\text {no NSA } t}=\frac{N_{t}\left(1-\tilde{s}_{0 t}\right)}{\widehat{\alpha}} \ln \left(1+\left(\sum_{i}^{F} \exp \left(\frac{\widehat{\delta}_{i t}+\widehat{\beta} \tilde{q}_{i t}-\widehat{\alpha} \tilde{p}_{i t}}{1-\widehat{\sigma}}\right)\right)^{1-\widehat{\sigma}}\right)
$$

\footnotetext{
32 For example, solving for a new equilibrium using estimated demand function and a changed ownership structure is a common method of simulating the effect of mergers on prices. Cf. Ivaldi and Verboven (2005).
} 
Consumer surplus under the NSA is likewise calculated but using observed prices and network quality.

$$
C S_{\mathrm{NSA} t}=\frac{N_{t}\left(1-s_{0 t}\right)}{\widehat{\alpha}} \ln \left(1+\left(\sum_{i}^{F} \exp \left(\frac{\widehat{\widehat{\delta}}_{i t}+\widehat{\beta} q_{i t}-\widehat{\alpha} p_{i t}}{1-\widehat{\sigma}}\right)\right)^{1-\widehat{\sigma}}\right)
$$

The difference between the two consumer surplus values indicates the impact of the NSA on consumer welfare.

\section{Estimation}

We apply our model to two NSAs that were implemented in the Czech Republic between TMCZ and O2 and that were signed in Q3-2013 and Q1-2014, respectively.

\subsection{The Czech mobile telecommunications industry}

In the Czech Republic three operators have a nationwide mobile network: TMCZ, O2 and Vodafone (VF). ${ }^{33} \mathrm{O} 2$ has contracted out the roll-out and operation of its mobile network to CETIN, though both firms are owned by the same investor. Market shares of the three MNOs in terms of active subscribers to mobile services in the period 2012-2018 are presented in Table 5-1. ${ }^{34}$

Table 5-1: Subscriber shares of Czech MNOs

\begin{tabular}{|c|c|c|c|c|}
\hline & & \multicolumn{3}{|c|}{ Operator } \\
\hline & & TMCZ & $\mathrm{O} 2$ & Vodafone \\
\hline \multirow{7}{*}{$\begin{array}{c}\text { Market } \\
\text { share }\end{array}$} & 2012 & $38 \%$ & $38 \%$ & $23 \%$ \\
\hline & 2013 & $38 \%$ & $39 \%$ & $22 \%$ \\
\hline & 2014 & $39 \%$ & $39 \%$ & $21 \%$ \\
\hline & 2015 & $40 \%$ & $38 \%$ & $22 \%$ \\
\hline & 2016 & $39 \%$ & $38 \%$ & $23 \%$ \\
\hline & 2017 & $40 \%$ & $36 \%$ & $24 \%$ \\
\hline & 2018 & $39 \%$ & $36 \%$ & $24 \%$ \\
\hline
\end{tabular}

Source: Authors' calculation based on data from Analysys Mason.

Apart from the MNOs there are several other firms that are active in the provision of mobile telecommunication services. MNOs own their respective spectrum to operate a mobile network but can rent spectrum to mobile virtual network operators (MVNOs). MVNOs can therefore buy access to a network to offer mobile telecommunication services and to compete with MNOs. Market shares presented in Table 5-1 include subscribers to MVNOs who use the network of their respective host MNO. The total market shares of MVNOs in the Czech Republic amount to $6.2 \%$ in 2018. In the following, however, we will restrict attention to the three MNOs TMCZ, $\mathrm{O} 2$ and VF who bear the costs of network deployment and realize potential cost savings of network sharing.

\footnotetext{
${ }^{33}$ Besides TMCZ, $\mathrm{O} 2$ and VF, Nordic Telecom is active in the Czech Republic as a small network operator that does not have a nationwide mobile network.

${ }^{34}$ The count of active subscribers to mobile services comprises total mobile handset and total mobile broadband connections and excludes subscribers who have not used their mobile account for more than three months.
} 
Two NSAs were concluded between TMCZ and O2: the first in the third quarter of 2013, comprising network sharing of the $2 \mathrm{G}$ and $3 \mathrm{G}$ technologies; the second in the second quarter of 2014, comprising network sharing of the $4 \mathrm{G}$ technology. The NSAs cover the entire Czech Republic apart from the two largest cities, Prague and Brno. The purpose of the NSAs was to facilitate the consolidation of the existing standalone $2 \mathrm{G} / 3 \mathrm{G}$ networks and to jointly roll-out $4 \mathrm{G}$. The NSAs are implemented via a geo split agreement, whereby each operator is responsible for the operation of sites in one part of country, excluding Prague and Brno. TMCZ operates the shared network in the West of the country as the Master operator with $\mathrm{O} 2$ as the Visitor operator. $\mathrm{O} 2$ operates the shared network in the East of the country as the Master operator with TMCZ as the Visitor operator. Besides sharing sites, the geo-split agreement also allows each operator to independently invest in sites that will not be shared, and the Visitor operator can also request from the Master operator additional unilateral investments to increase the network quality for the Visitor operator's subscribers.

Cost savings realized differ between the $2 \mathrm{G}, 3 \mathrm{G}$ and $4 \mathrm{G}$ technologies. The $2 \mathrm{G}$ and $3 \mathrm{G}$ network has already reached maturity at the time of the signature of the 2G/3G NSA; hence, cost savings can be realized from the decommissioning of sites as the formation of a common grid rendered some sites to become redundant or to be operated. Cost savings related to the $4 \mathrm{G}$ technology, instead, are realized because each of the sharing parties needs to roll out and operate fewer sites, resulting in an avoidance of network duplication costs in the first place. Due to the short period between the conclusion of both NSAs it is empirically not possible to disentangle the effects of both NSAs. In our model we will thus estimate the joint effects of both NSAs, thus capturing network sharing over all available network technologies.

\subsection{Data}

The Structural model relies on four essential elements of data to estimate the effects of the NSAs: data on market shares, prices, network quality and network deployment. Based on the availability of data in different sources, the model will be estimated over the period Q1-2012 to Q4-2017.

\subsubsection{Analysys Mason data}

Data on market shares and prices are taken from Analysys Mason's (AM) Telecoms Market Matrix for Central and Eastern Europe. This database provides quarterly data for the Czech mobile sector, broken down by operator, starting from Q1-2004 until Q1-2019. The proxy to derive market shares is the total number of active subscribers to mobile services per operator..$^{35}$ This measure reflects the provision of mobile telecommunication services and is in line with the EC's approach in calculating market shares in the telecommunications industry in some past cases. ${ }^{36}$ It approximates the probability that an

\footnotetext{
${ }^{35}$ The number of subscribers to mobile services is the sum of total mobile handset and total mobile broadband connections. It includes prepaid and contract subscribers and excludes machine to machine connections.

${ }^{36}$ See Case COMP/M.6497 - Hutchison 3G Austria / Orange Austria; Case COMP/M.6992, - Hutchinson 3G UK / Telefonica Ireland; Case M.7018 - Telefonica Deutschland/ E-Plus; Case M.7612 - Hutchinson 3G UK / Telefonica UK; Case M.7758-Hutchinson 3G Italy /Wind / JV. The EC also declared in previous decisions that voice and data services do not constitute separate relevant markets: See: Case COMP/M.6497 - Hutchison 3G Austria / Orange Austria, Case COMP/M.5650 - T-Mobile/Orange, Case COMP/M.4947 - Vodafone/Tele2 Italy/Tele2 Spain; Case COMP/M.6992, - Hutchinson 3G UK / Telefonica Ireland; Case M.7018 - Telefonica Deutschland/ E-Plus; Case M.7612 - Hutchinson 3G UK / Telefonica UK; Case M.7758-Hutchinson 3G Italy /Wind / JV.
} 
average $\mathrm{CZ}$ citizen chooses a specific operator or services. The measure for the price charged by MNOs is the average revenue per user (ARPU), which equals revenue derived from all services divided by the total number of subscribers. ${ }^{37}$ The benefit of the ARPU, compared to consumer expenditure data, is that it is easily available for all operators in the Czech Republic. This allows to include Vodafone, the third largest MNO in the Czech Republic, in the econometric analysis, which is crucial for identification. The shortcoming of using ARPU is that, by definition, it relates to total revenues per subscriber, which can depend on the usage by a subscriber for a given price, so ARPU may reflect changes in the composition of consumption rather than real price changes.

\subsubsection{Ookla data}

The proxy for network quality is the average download speed experienced by the users of mobile networks. Data on download speed is obtained from the data provider Ookla, a leading mobile internet data provider. ${ }^{38}$ Ookla hosts a platform that allows mobile network users to conduct speed tests and thus allows to represent actual customer experience of a network. Users can test their mobile internet connection through a mobile browser or by downloading the Ookla application on their mobile phone. Each time a user runs a speed test, Ookla records the time and location of the test, the operator and technology being used along with several metrics, among those the average download speed.

Data on mobile download speed is available per operator and access technology (2G, 3G and 4G/LTE) on a quarterly basis both at the disaggregated district level and the aggregated national level. Ookla derives download speed through the aggregation of individual user-level information by segregating user-samples into subsets and computing statistics on these subsets. To obtain the aggregated download speed over all technologies at a national level in a given year, first the individual-level average download speed of all tests per user in the country and year is derived. The national aggregated download speed is then derived by computing the average of the individual-level download speeds per user. ${ }^{39}$

\footnotetext{
${ }^{37}$ The ARPU does not consider subscribers who have not used their mobile account for more than three months, as these are not active subscribers.

${ }^{38}$ See "http://www.speedtest.net/mobile/", accessed on 21 January 2020. The network performance metrics provided by Ookla are very reliable (i.e. representative of the population) and have previously been used by the GSMA in their evaluation of the Hutchinson/Orange merger in Austria (see GSMA (2017)). Moreover, MNOs are themselves relying on Ookla data in advertising the quality of their network and benchmarking it against the network of competitors.

${ }^{39}$ With millions of tests taken each day, Ookla employs a sampling procedure to ensure that every user gets a fair representation in the final analysis. This means, for example, that tests from heavy testers (i.e. users who take multiple tests within a short period of time) and casual testers (i.e. users who test their download speed seldomly) are appropriately weighted (further details can be found in Ookla's Methodology document, available at https://www.speedtest.net/awards/methodology, accessed on 21 January 2020). Ookla also employs various techniques to eliminate biases. This includes, for example, blacklisting suspicious tests, removing tests with a different pre-test and post-test connection type, filtering out of roaming tests (i.e. tests taken by people who are roaming in the Czech Republic), removing tests from MVNOs or removing tests with a latency greater than the 97th percentile.
} 
In accordance with the level of aggregation for the price and quantity data, we consider aggregated download speed at the national level, which is provided by Ookla for the period from Q1-2012 to Q42017 and calculated according to the Ookla sampling procedure. ${ }^{40}$

\subsubsection{Network deployment data}

Installed network capacity has an impact on network quality. If network capacity is insufficient to serve network traffic, holding everything else constant, increasing capacity increases the effective quality of the network that consumers experience. Higher network capacity can be achieved, for example, by adding more spectrum or by deploying more sites. Information on the number of sites with installed capacity for each technology was obtained for the three main MNOs, TMCZ, 02 and Vodafone over the period from 2012 to $2017 .{ }^{41}$ For each operator, the site data contain all the sites in the Czech Republic and include information on the amount of deployed spectrum and installed capacity per site, separated by technology (i.e. TRX for GSM, carriers for UMTS and resource blocks for LTE). For TMCZ and $\mathrm{O} 2$, the data also allows to identify whether a site is shared or not. ${ }^{42}$ Installed capacities are aggregated at the district level based on the location of each site.

To estimate the effects of the NSAs, especially the sharing status of 4G/LTE sites will be important. $4 G / L T E$ sites are deployed after the NSA, while $2 \mathrm{G}$ and $3 \mathrm{G}$ have already been employed independently throughout the country before the NSA and are considered as mature technologies. Cost savings from network sharing are thus most likely to be realized by the sharing of $4 G / L T E$ sites. A shared $4 G$ site is defined to have at least one shared spectrum deployment in any of the available LTE spectrum bands. A non-shared $4 \mathrm{G}$ site is defined to have at no shared spectrum deployment in any of the LTE spectrum bands.

\subsection{Results}

This section presents the results after implementing the described estimation steps in Sections 3.1, 3.2 and 3.3. We start with the estimation of demand.

\subsubsection{Demand estimation}

Based on equation (2), which describes consumer demand in terms of market shares for each operator, it is necessary to select the explanatory and instrumental variables to be used in the estimation. We use the following "baseline specification" to describe consumer demand for mobile telecommunication services in the Czech Republic:

$$
\ln \left(\frac{s_{i t}}{s_{0 t}}\right)=\mu_{0}+\beta q_{i t}-\alpha p_{i t}+\sigma \ln \left(s_{i \mid g t}\right)+\rho g_{i t}^{4 G}+\theta_{i} \mu_{i}+\xi_{i t}
$$

\footnotetext{
${ }^{40}$ The disaggregated Ookla data at the district level is used in the reduced-form analysis presented in Section 6.

${ }^{41}$ This information was obtained based on public information available at http://gsmweb.cz/, enhanced with information received from Deutsche Telekom in the context of the European Commission case AT.40305.

42 Installed capacity depends also on (i) density of the sites and (ii) spectrum efficiency deployment (MIMO).
} 
The explanatory variables include network quality measured by average download speeds $\left(q_{i}\right)$, prices measured by the ARPU $\left(p_{i t}\right)$, market shares $\left(s_{i t}, s_{0 t}\right.$, and $\left.s_{i \mid g t}\right)$, an indicator for $4 \mathrm{G}$ coverage $\left(g_{i t}^{4 G}\right)$, operator fixed effects $\left(\mu_{i}\right)$ and a constant $\mu_{0}$.

The variable for $4 \mathrm{G}$ coverage measures the total amount of $4 \mathrm{G}$ spectrum in $\mathrm{MHz}$ that is deployed on shared and non-shared sites. ${ }^{43}$ This variable allows to account for the heterogeneity among TMCZ, $\mathrm{O} 2$ and Vodafone in terms of their mobile network while, at the same time, allows to capture the evolution of demand towards more data-intensive mobile telecommunications services that require an increasing amount of network capacity. ${ }^{44}$

To make sure that the demand function is estimated consistently, the endogeneity problem that arises from the simultaneous relationship between network quality, prices and quantities (market shares) needs to be accounted for. The three variables are determined jointly because network quality and prices affect the quantity demanded, while the quantity demanded also affects MNOs' choices of network quality and prices. A total of six instruments are used in the estimation. The first three instruments capture the one-quarter lagged prices, within-nest market shares and network quality (download speed). These instruments are often used in the literature because the current period error term cannot influence past values of the endogenous variables. ${ }^{45}$ Two additional instruments capture the one-quarter lagged network quality (download speed) of each of the MNO's two competitors. In the literature, it is common to use characteristics of products of rival firms as instruments, also known as BLP-type instruments. ${ }^{46}$ Finally, the sixth instrument captures the one-quarter lagged prices in Slovakia, the Czech Republic's neighboring country. The motivation to include this instrument is that cost shocks should affect operators' pricing decisions in a similar way in neighboring markets, while consumer preferences across neighboring markets are not necessarily correlated. Both $\mathrm{O} 2$ and TMCZ operate in Slovakia and it is possible that prices in this neighboring market can explain prices in the Czech Republic, for example if price changes are driven by unobserved cost shocks that are common in the two countries but unrelated to demand in the Czech Republic. ${ }^{47}$ These types of instruments are widely used in the literature and known as Hausman-type instruments. ${ }^{48}$

Table 5-2 presents the results of the baseline estimation. Several robustness checks have been conducted to demonstrate that the presented results do not hinge on the inclusion of specific explanatory variables, instruments or estimation methods. These robustness checks are presented in Section 7.1, showing that the presented findings from the baseline specification can be confirmed if: (i) different subsets of instruments are used; (ii) an alternative measure of $4 \mathrm{G}$ coverage; (iii) $2 \mathrm{G}$ and

\footnotetext{
${ }^{43}$ As shown in Section 7.1.2, results are similar if instead the number of resource blocks is used as a measure of $4 \mathrm{G}$ coverage.

${ }^{44}$ The baseline estimation only includes an indicator for total $4 \mathrm{G}$ spectrum. As shown in Section 7.1.3 however, robustness checks also including indicators for $2 \mathrm{G}$ and $3 \mathrm{G}$ spectrum yield very similar results.

${ }^{45}$ See Arellano, M., \& Bover, O. (1995) and Blundell, R., \& Bond, S. (1998).

${ }^{46}$ See Berry, Levinsohn, \& Pakes (1995).

47 Vodafone is not operating in Slovakia; therefore, the price of the third large mobile network operator in Slovakia, Orange, is used as an instrument for the price of Vodafone in the Czech Republic. Even though Orange and Vodafone are different operators, the price of Orange in Slovakia is highly correlated with the price of Vodafone in the Czech Republic with a correlation coefficient of 0.84 , thus satisfying the relevance condition.

${ }^{48}$ See Nevo (2000).
} 
3G coverage is additionally included; (iv) year fixed effects are included; (v) data traffic is used as a proxy for $4 \mathrm{G}$ coverage; and (vi) no instruments are used and the model is estimated with simple OLS.

Table 5-2: Demand function estimates

\begin{tabular}{|c|c|}
\hline In(Market share) & \\
\hline Price $(-\alpha)$ & $\begin{array}{l}-0.0127 * * * \\
(-12.49)\end{array}$ \\
\hline Avg. download speed ( $\beta$ ) & $\begin{array}{l}0.00837 * * * \\
(11.75)\end{array}$ \\
\hline Market share within group $(\sigma)$ & $\begin{array}{l}0.830 * * * \\
(5.26)\end{array}$ \\
\hline 4G spectrum $(\mathrm{MHz})$ & $\begin{array}{l}0.00268 * * * \\
(4.16)\end{array}$ \\
\hline \multicolumn{2}{|l|}{ Operator FE: } \\
\hline $\mathrm{TMCZ}$ & $\begin{array}{l}-0.0321 * * * \\
(-3.02)\end{array}$ \\
\hline Vodafone & $\begin{array}{l}-0.0989 \\
(-1.09)\end{array}$ \\
\hline Constant & $\begin{array}{l}1.498 * * * \\
(8.42)\end{array}$ \\
\hline Observations & 72 \\
\hline Adj. $\mathrm{R}^{2}$ & 0.988 \\
\hline Over-identification test ( $\mathrm{p}$-value) & 0.141 \\
\hline
\end{tabular}

As predicted by economic theory, the demand for mobile telecommunication services depends negatively on price and positively on the level of network quality (i.e. average download speed). In addition, the $4 \mathrm{G}$ coverage coefficient is positive and significant. The coefficient of the within group market shares represents the degree to which customers prefer one of the main operators, as opposed to the outside option. Its value of 0.83 is relatively high but different from 1 , suggesting that consumers who decide to contract with one of the main operators are unlikely to switch to the outside option. Since there are more instruments than endogenous variables, one can conduct the HansenSargan test of over identification, testing the null hypothesis that the instruments are exogenous. The p-value associated with this test is 0.141 , implying that the null hypothesis cannot be rejected. ${ }^{49}$

Following the demand estimation, it is possible to calculate various metrics that shed more light on consumer demand. First, note that consumers' willingness to pay for quality can be computed by the ratio of the coefficients for download speed over the coefficient for price $\left(\frac{\beta}{\alpha}\right)$. This ratio expresses the willingness-to-pay for one additional Mbit/s of download speed to derive the same level of utility. It is

\footnotetext{
${ }^{49}$ At least four instruments are needed for the estimation and the corresponding implementation of the HansenSargan test. Different subsets of the instruments used in the baseline model display similar results. However, it seems that the inclusion of the lagged within-nest market share is needed in order to identify the nest coefficient $\sigma$. The results are robust to using different combinations of instruments, as presented in Section 7.1.1.
} 
given by $0.66 \frac{€}{\mathrm{Mbits} / \mathrm{s}}$, indicating that a representative user is willing to pay $€ 0.66$ for one additional Mbit/s of download speed.

Second, Table 5-3 reports the average own and cross-price elasticity of demand for each MNO, resulting from the demand specification. Average demand elasticities are reported before the NSAs were signed (i.e. before Q1-2014) and after the NSAs were signed (i.e. after Q1-2014) to analyze whether the implementation of the NSAs went along with a change in demand elasticities. ${ }^{50}$ Ownprice elasticities for all MNOs are negative and above 1 in absolute value before Q1-2014. After Q12014, own-price elasticities became smaller in absolute value, indicating that consumers are getting less responsive to price changes over time. This finding can be explained by the increasing importance of mobile telecommunication services for consumers over time, as will be shown in Table 5-4. Crossprice elasticities of demand for all MNOs are positive but are also becoming smaller after Q1-2014, indicating that consumers are getting less responsive to price changes over time. This finding is in line with the observed pattern for own-price elasticities.

Table 5-3: Own and cross-price elasticities of demand

\begin{tabular}{|c|c|c|c|c|c|}
\hline \multirow[b]{2}{*}{ Operator } & \multirow[b]{2}{*}{ NSA } & \multirow{2}{*}{$\begin{array}{l}\text { Own price } \\
\text { elasticity }\end{array}$} & \multicolumn{3}{|c|}{$\begin{array}{l}\text { Cross price elas ticity } \\
\text { with respect to a price change by }\end{array}$} \\
\hline & & & TMCZ & $\mathbf{O 2}$ & Vodafone \\
\hline $\mathrm{O} 2$ & & -1.95 & 1.12 & - & 0.71 \\
\hline TMCZ & Before & -1.92 & - & 1.14 & 0.71 \\
\hline Vodafone & & -2.50 & 1.12 & 1.14 & - \\
\hline $\mathrm{O} 2$ & & -1.47 & 0.86 & - & 0.55 \\
\hline TMCZ & After & -1.39 & - & 0.85 & 0.55 \\
\hline Vodafone & & -1.98 & 0.86 & 0.85 & - \\
\hline
\end{tabular}

Source: Authors' calculation.

Third, Table 5-4 reports the average own- and cross-elasticities of demand with respect to a change in quality for each MNO. ${ }^{51}$ Own-quality elasticities of demand for all MNOs are positive and are increasing over time, which is expected because mobile download speed is getting more important. Cross-quality elasticities of demand for all MNOs are negative and are increasing over time in absolute value, which indicates that consumers are becoming more responsive to changes in network quality. This finding again supports the intuition that download speed becomes more important for consumers over time.

50 In the nested logit model framework, the formula for the own-price elasticity of demand is given by $\eta_{i i}=$ $-\frac{\widehat{\alpha}}{1-\widehat{\sigma}} p_{i t}\left(1-\hat{\sigma} s_{i \mid g t}-(1-\hat{\sigma}) s_{i t}\right)$; the formula for the cross-price elasticity of demand for firm $j$ with respect to a change in price of firm $l$ is given by $\eta_{j i}=\frac{\widehat{\alpha}}{1-\hat{\sigma}} p_{i t}\left(\hat{\sigma} s_{i \mid g t}-(1-\hat{\sigma}) s_{i t}\right)$.

${ }^{51}$ In the nested logit model framework, the formula for the own-elasticity of demand with respect to quality is given by $\kappa_{i i}=$ $\frac{\widehat{\beta}}{1-\widehat{\sigma}} q_{i t}\left(1-\hat{\sigma} s_{i \mid g t}-(1-\hat{\sigma}) s_{i t}\right)$; the formula for the cross-elasticity of demand for firm $j$ with respect to a change in quality of firm $i$ is given by $\kappa_{j i}=-\frac{\widehat{\beta}}{1-\hat{\sigma}} q_{i t}\left(\hat{\sigma} s_{i \mid g t}-(1-\hat{\sigma}) s_{i t}\right)$. 
Table 5-4: Own and cross elasticities of demand for network quality

\begin{tabular}{|c|c|c|c|c|c|}
\hline \multirow[b]{2}{*}{ Operator } & \multirow[b]{2}{*}{ NSA } & \multirow{2}{*}{$\begin{array}{c}\text { Own } \\
\text { quality } \\
\text { elasticity }\end{array}$} & \multicolumn{3}{|c|}{$\begin{array}{l}\text { Cross quality elasticitiy } \\
\text { with respect to quality change by }\end{array}$} \\
\hline & & & TMCZ & $\mathbf{O 2}$ & Vodafone \\
\hline $\mathrm{O} 2$ & & 0.09 & -0.10 & - & -0.06 \\
\hline TMCZ & Before & 0.18 & - & -0.05 & -0.06 \\
\hline Vodafone & & 0.22 & -0.10 & -0.05 & - \\
\hline $\mathrm{O} 2$ & & 0.57 & -0.38 & - & -0.28 \\
\hline TMCZ & After & 0.61 & - & -0.33 & -0.28 \\
\hline Vodafone & & 1.00 & -0.38 & -0.33 & - \\
\hline
\end{tabular}

Source: Authors' calculation.

\subsubsection{Cost estimation}

As explained in Section 4.2, MNO's marginal costs of providing access to the network $c_{i t}$ (quantity cost) as well as MNO's quality cost parameter $k_{i t}$ can be recovered after the estimation of demand. In this section, we provide an econometric specification that describe how these costs depend on each MNO's deployed network. We use the following "baseline specification" for marginal quantity costs:

$$
\begin{aligned}
& c_{i t}=c_{0}+\theta_{i} \mu_{i}+\gamma \text { year }_{t}+\phi \text { quarter }_{t} \\
& +\rho^{\text {shared }} \text { shared_sites }{ }_{i t}^{4 G}+\rho^{\text {nonshared }} \text { nonshared_sites } s_{i t}^{4 G}+M T R_{t}+\omega_{i t} \text {. }
\end{aligned}
$$

The explanatory variables include firm, year and quarterly fixed effects, the number of shared and non-shared 4G sites of operator I and period t (shared_sites ${ }_{i t}^{4 G}$, nonshared_sites ${ }_{i t}^{4 G}$ ) and mobile termination rates at period $\mathrm{t}$ that are common to all operators $\left(M T R_{t}\right)$.

The baseline specification explains quantity costs in terms of the number of shared and non-shared 4G sites and additional explanatory variables. Firm fixed effects are important to control for firmspecific factors affecting costs that are constant over time. Year fixed effects are important to control for unobserved factors affecting costs in a given year common to all firms and could capture trends in costs over time. Mobile termination rates are important as they are a direct driver of firms' costs.

Most importantly, and as explained in Section 4.3, the baseline specification identifies whether the NSAs generated cost reductions for TMCZ and O2, compared to Vodafone that exclusively operated a non-shared network. This is achieved by testing whether there is a difference in costs between installing capacity in shared and non-shared 4G sites. ${ }^{52}$ Intuitively, capacity deployed in shared sites could result in a cost advantage compared to deployment in a non-shared site, for example, because the same number of customers could be served by a lower number of independent sites. The presented baseline regression thus allows to directly measure the cost effects of network sharing by relying on information on the number of shared and non-shared sites.

A similar procedure is used to estimate the quality costs parameter. The baseline specification is expressed as follows:

\footnotetext{
${ }^{52}$ Because the deployment of $2 \mathrm{G}$ and $3 \mathrm{G}$ was already completed at the time the NSAs were signed, the costs of installing 2G/3G capacity are covered or sunk. Therefore, differences in costs between shared and non-shared sites when installing $2 \mathrm{G} / 3 \mathrm{G}$ capacity are not taken into account.
} 


$$
\begin{aligned}
& k_{i t}^{T}=c_{0}+\theta_{i} \mu_{i}+\text { ryear }_{t}+\rho^{\text {shared }} \text { shared_sites } \\
& +\rho^{\text {nonshared }} \\
& \text { nonshared_sites } \\
& \text { it }
\end{aligned}
$$

with $T \in\{G S, \mathrm{JV}\}$ indicating the quality cost parameter in the geo-split and JV equilibrium, respectively. Compared to the estimation of marginal costs of providing access to the network $c_{i t}$, it is not necessary to include quarter fixed effects because the quality cost parameter $k_{i t}^{T}$ shows no pattern of seasonality.

Table 5-5 presents the results of the baseline cost estimations. Several robustness checks have been implemented to demonstrate that the presented results do not hinge on the inclusion of specific explanatory variables or estimation methods. These robustness checks are presented in Section 7.2 and show that the results can be confirmed if: (i) trends or period fixed effects are used instead of year fixed effects and (ii) the effect of the NSA is identified alternatively by using an operator-specific dummy after Q1-2014 instead of exploiting differences in the number of sites.

Column (1) of Table 5-5 shows the results of the regression of marginal quantity costs $c_{i t}$; while columns (2) and (3) show the results of the regressions of the quality cost parameter in the geo-split and JV equilibrium, respectively. Costs are estimated over the period Q1-2013 until Q4-2017 as this is the period when information on both shared on non-shared $4 \mathrm{G}$ sites is available. ${ }^{53}$

\begin{tabular}{|c|c|c|c|}
\hline & $\begin{array}{c}\text { (1) } \\
\text { Marginal cost } \\
\text { per user }\end{array}$ & $\begin{array}{c}(2) \\
\text { Quality cost } \\
\text { parameter } \\
\text { (competitive eq.) }\end{array}$ & $\begin{array}{c}\text { (3) } \\
\text { Quality cost } \\
\text { parameter (hyrid } \\
\text { eq.) }\end{array}$ \\
\hline Shared $4 \mathrm{G}$ sites & $\begin{array}{l}1.136^{* * *} \\
(3.66)\end{array}$ & $\begin{array}{l}0.0379^{* *} \\
(2.18)\end{array}$ & $\begin{array}{l}0.0714^{* * *} \\
(3.94)\end{array}$ \\
\hline Non-shared 4G sites & $\begin{array}{l}2.307^{* * *} \\
(4.98)\end{array}$ & $\begin{array}{l}0.107^{* * *} \\
(3.67)\end{array}$ & $\begin{array}{l}0.157^{* * * *} \\
(5.16)\end{array}$ \\
\hline MTR & $\begin{array}{l}8.175^{* * *} \\
(6.64)\end{array}$ & $\begin{array}{l}0.172 * \\
(1.83)\end{array}$ & $\begin{array}{l}0.170^{*} \\
(1.80)\end{array}$ \\
\hline \multicolumn{4}{|l|}{ Operator FE: } \\
\hline TMCZ & $\begin{array}{l}-2.023 * * * \\
(-6.32)\end{array}$ & $\begin{array}{l}-0.0883 * * * \\
(-3.96)\end{array}$ & $\begin{array}{l}-0.0937 * * * \\
(-4.07)\end{array}$ \\
\hline Vodafone & $\begin{array}{l}3.238^{* * *} \\
(4.61)\end{array}$ & $\begin{array}{l}-0.304^{* * *} \\
(-6.35)\end{array}$ & $\begin{array}{l}-0.293 * * * \\
(-5.84)\end{array}$ \\
\hline Constant & $\begin{array}{l}3.487^{*} \\
(1.90)\end{array}$ & $\begin{array}{l}0.189 \\
(1.39)\end{array}$ & $\begin{array}{l}0.175 \\
(1.30)\end{array}$ \\
\hline Observations & 60 & 60 & 60 \\
\hline Adj. $R^{2}$ & 0.960 & 0.830 & 0.843 \\
\hline Quarter fixed effects & Yes & No & No \\
\hline Year fixed effects & Yes & Yes & Yes \\
\hline
\end{tabular}

Table 5-5: Baseline cost regressions

Notes: ${ }^{*} p<0.10,{ }^{* *} p<0.05,{ }^{* * *} \mathrm{p}<0.01$. Operator fixed effects are relative to 02 , the omitted MNO. Source: Authors' calculation.

\footnotetext{
53 In contrast to the demand estimation presented in Section 5.3.1, we do not include 2012 in the estimation because there were no shared $4 \mathrm{G}$ sites in 2012 that would allow us to observe a differential impact of shared vs. nonshared $4 \mathrm{G}$ sites on costs.
} 
The baseline cost estimations show that the costs of deploying an additional non-shared $4 \mathrm{G}$ site is always more expensive than deploying an additional shared $4 G$ site - in fact roughly twice as expensive. These results confirm that the cost savings for TMCZ and $\mathrm{O} 2$ are generated through network sharing, by using shared instead of non-shared sites. The model thus identifies the mechanism by which network sharing generates cost efficiencies. In addition, the model can be used to predict how costs would have developed if the NSAs had not been in place, as explained in Section 4.3.

After having obtained an estimate for the quality cost parameter $k_{i t}^{T}$, we performed a Vuong test to test whether the geo-split or the JV equilibrium provides a more realistic representation of the data generating process. This test is a non-nested model selection test used to assess which type of quality cost parameter fits the observed data better and is thus more likely to correspond to the true model of competition. The obtained Vuong test statistic is 0.34 , suggesting that the two types of equilibria are statistically not distinguishable. ${ }^{54}$ As a consequence, to clarify which equilibrium model is more likely to be the true one, both quality cost parameters are used to simulate the counterfactual equilibrium to assess which equilibrium yields more realistic results.

\subsubsection{Geo-split equilibrium}

This section presents the results after simulating the counterfactual equilibrium, assuming that MNOs do not coordinate on network quality to maximize joint efforts, but that each MNO independently sets the profit-maximizing level of network quality, resulting in a quality cost parameter presented by equation (10). This means that counterfactual marginal quantity costs $\tilde{c}_{i t}$ and counterfactual costs of providing network quality $\tilde{k}_{i t}^{J V}$ are derived based on the results of the baseline demand and cost estimation. Counterfactual costs are then used to solve for the corresponding equilibrium counterfactual prices, market shares and network quality.

Because Vodafone does not participate in the NSAs and therefore does not deploy shared sites, our model predicts that its counterfactual costs are equal to its actual costs. In reality, Vodafone's quantity costs could also be affected because the NSAs could change Vodafone's investment decisions in network infrastructure. Infrastructure investments are likely to be strategic complements, implying that Vodafone's reaction to the implementation of the NSA would have been to also increase its own level of network deployment. If this is true, Vodafone's marginal costs in the counterfactual scenario

\footnotetext{
${ }^{54}$ The Vuong test is asymptotically follows a standard normal distribution with a critical value at a $95 \%$ level of significance of $|1.96|$. A value of the Voung test smaller than |1.96| suggest that the two competing models of competition are statistically not distinguishable. It should be noted, though that the sample size of the Vuong test in this case was 60 observations, which might be too small to guarantee that the test statistic approximately follows a standard normal distribution.
} 
without the NSAs in place would have been higher because economies of scale, scope and density would be harder to realize. ${ }^{55,56}$

Evidence that Vodafone's costs are also affected by the NSAs is found by computing the counterfactual equilibrium, adjusting TMCZ's and O2's (i.e. $\tilde{c}_{i t}$ and $\tilde{k}_{i t}^{J V}$ ) counterfactual costs as described but keeping Vodafone's costs unchanged. Figure 5-1 depicts the resulting counterfactual download speed for each MNO in this scenario. It can be observed that the resulting counterfactual download speed for each operator if no NSA had been signed is unrealistic, predicting that TMCZ's and O2's download speed had decreased by $79 \%$ and $76 \%$, respectively, to near zero levels, while download speed of Vodafone had increased by $176 \%$. This unrealistic result shows that there exists no credible counterfactual scenario that features higher counterfactual costs of TMCZ and O2, without adjusting for a Vodafone's costs.

Figure 5-1: Counterfactual download speed (geo-split equilibrium, Vodafone costs unchanged)
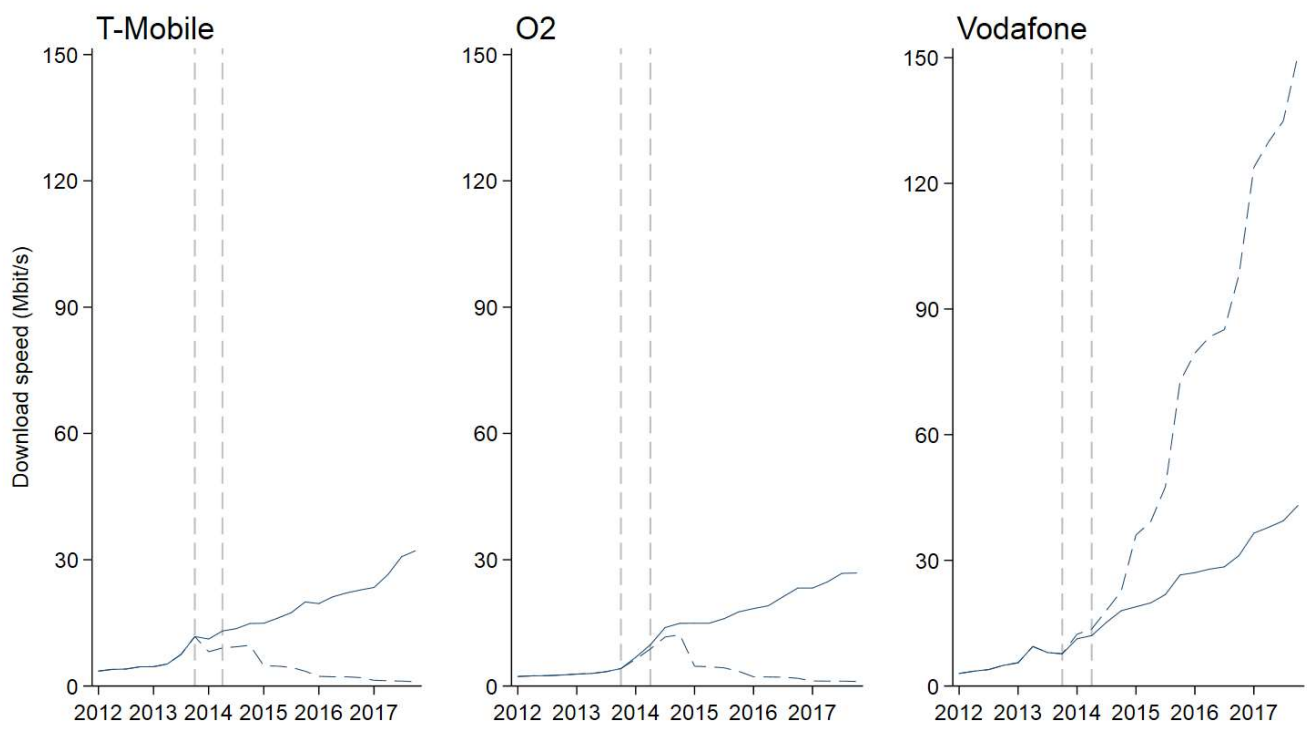

Observed speed

Counterfactual

Notes: The first dashed line refers to the signing date of 2G/3G NSA, the second line to the signing date of the 4G/LTE NSA.

Source: Author's analysis.

\footnotetext{
${ }^{55}$ For instance, Briglauer et al. (2016) use firm-level panel data to examine the impact of service-based and facility-based competition on firm-level investment in the fixed broadband industry. The dataset contains information of 57 operators based in $23 \mathrm{EU}$ countries during the period 2003-2012. Based on the impact of the incumbents and entrants infrastructure stock on firm's levels of investments, the authors argue that investments in infrastructure seem to be strategic complements. In a similar vein, Grajek and Röller (2012) find evidence of strategic complementarity of investments (but from entrants to incumbents only), as incumbents seem to invest more in response to investment increases of entrants. The dataset used covers more than 70 fixed-line telecom operators in $20 \mathrm{EU}$ member states during the period 1997-2006.

${ }^{56}$ We do not model MNOs investments in network infrastructure but instead describe how network capacity would have been deployed by taking the total level of capacity, resulting from investments in infrastructure, as given. A potential extension of the model could allow firms to choose the number of shares/non-shared sites at the same time as choosing quality and prices. Due to the evidence of strategic complementarities in investments in network infrastructure in the literature, we do believe, however, that this increased level of complexity is not necessary to anticipate the effects of NSAs on the costs of outsiders to the NSAs.
} 
For this reason, the counterfactual equilibrium in prices and network quality is derived by assuming that counterfactual quantity and quality costs for Vodafone would have been affected by a similar magnitude as the costs for TMCZ and O2. Specifically, based on the cost estimation, the average increase in marginal costs of quantity for TMCZ and $\mathrm{O} 2$ in the absence of the NSA is estimated to be $40.4 \%$ and $33.6 \%$, respectively. We thus assume that Vodafone's marginal costs of quantity would also have been $33 \%$ higher in the absence of the NSAs. ${ }^{57}$ We further assume that Vodafone's quality cost parameter $\tilde{k}_{i t}^{G S}$ would have been higher in the absence of the NSAs, in line with the prediction for the quality cost parameter of TMCZ and $\mathrm{O} 2$ demonstrated in Table 5-5. Section 7.3 shows that the qualitative results are robust to different assumptions on the change in $\tilde{k}_{i t}^{G S}$; for the presentation of the baseline results we assume that the counterfactual quality cost parameter $\tilde{k}_{i t}^{G S}$ for all MNOs would be $20 \%$ higher than the derived quality cost parameter $k_{i t}{ }^{58}$

Higher costs in the absence of the NSA for TMCZ and $\mathrm{O} 2$ result in higher prices being charged. Figure 5-2 displays the estimated counterfactual equilibrium prices for all MNOs. On average, prices for TMCZ, $\mathrm{O} 2$ and Vodafone would be $14.8 \%, 14.6 \%$ and $12.5 \%$ higher without the NSAs, respectively.

Figure 5-2: Development of observed and counterfactual prices
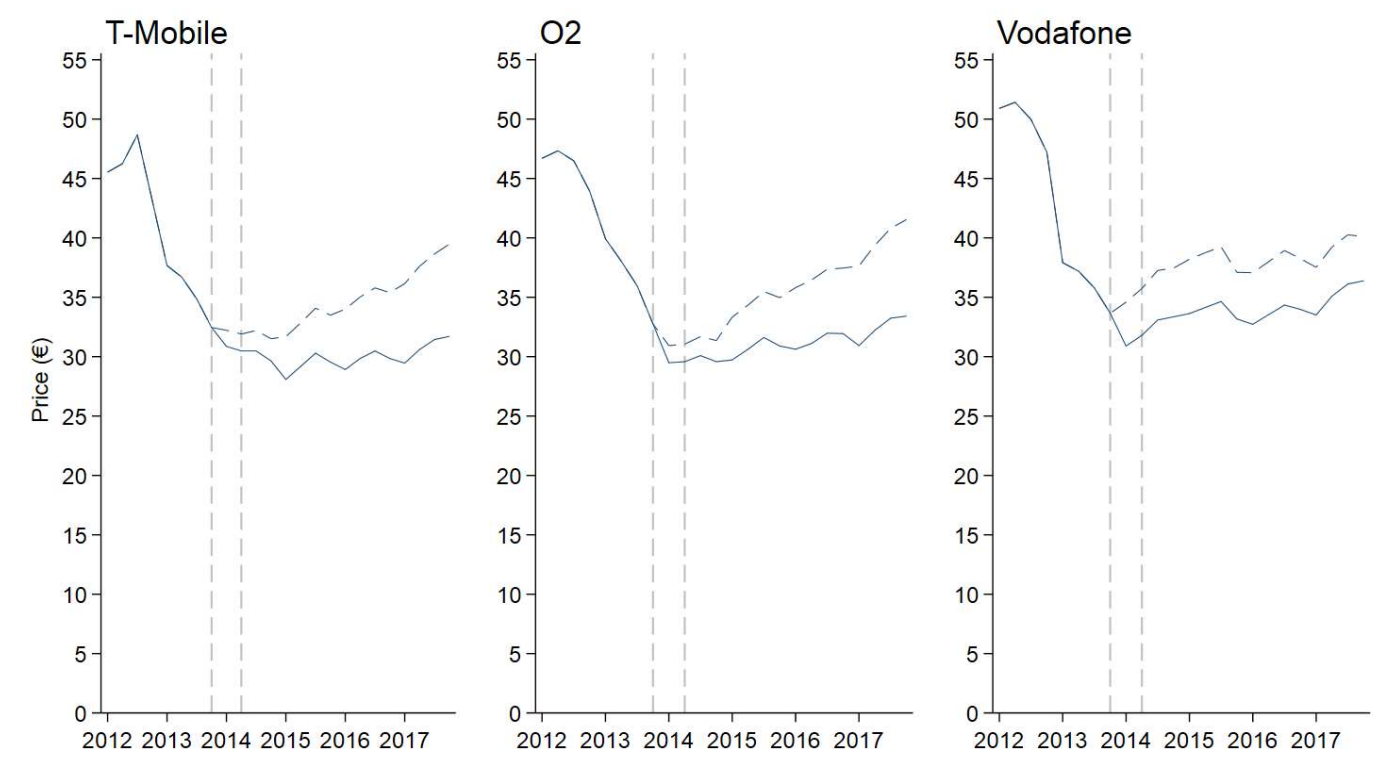

Observed price

Counterfactual

Notes: The first dashed line refers to the signing date of 2G/3G NSA, the second line to the signing date of the 4G/LTE NSA.

Source: Author's analysis.

Figure 5-3 displays the estimated counterfactual network quality for all MNOs. It can be observed that counterfactual levels of network quality do not take unrealistic values if it is assumed that Vodafone's costs are also affected by the NSA. On average, network quality for TMCZ, $\mathrm{O} 2$ and Vodafone would be $11.3 \%, 9.8 \%$ and $44.3 \%$ lower, respectively.

\footnotetext{
${ }^{57}$ As it turns out, the smallest possible increase in costs for Vodafone that allows convergence to a counterfactual equilibrium is $33 \%$. In other words, there cannot exist a counterfactual scenario with higher costs for TMCZ and $\mathrm{O} 2$ of $40.4 \%$ and $33.6 \%$ respectively, without observing an increase in costs for Vodafone of at least $33 \%$.

${ }^{58}$ Specifically, qualitative results remain unchanged for changes of $\tilde{k}_{i t}^{G S}$ in the range of $5 \%$ and $30 \%$.
} 
Figure 5-3: Development of observed and counterfactual network quality
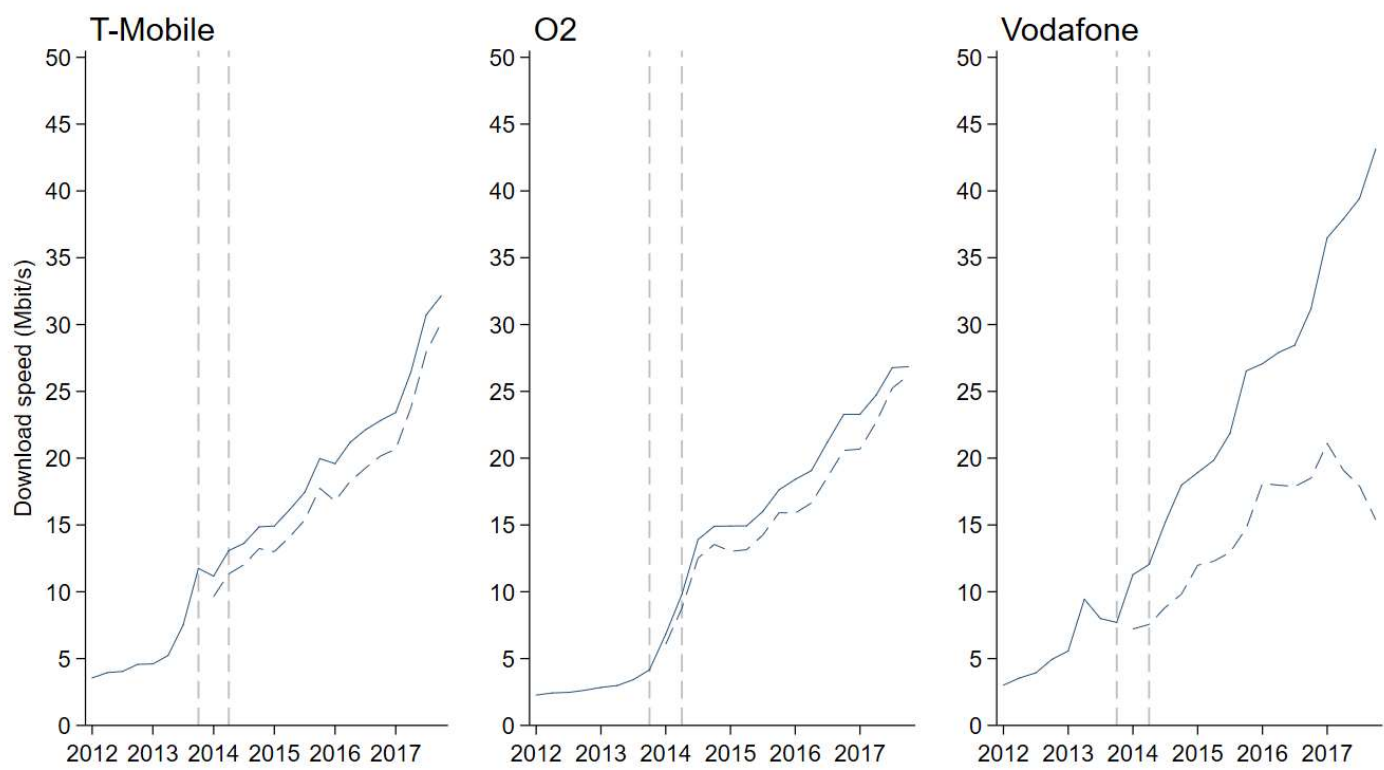

Observed speed

Counterfactual

Notes: The first dashed line refers to the signing date of 2G/3G NSA, the second line to the signing date of the 4G/LTE NSA.

Source: Author's analysis.

Finally, in terms of consumer welfare, consumers would have been worse off without the NSAs. Applying the formulas for consumer surplus presented in equations (17) and (18) shows that consumer surplus per quarter would have been on average $5.9 \%$ lower (or equivalently, an average of $€ 111.1$ million. per quarter). ${ }^{59}$

\subsubsection{JV equilibrium}

This section presents the results after simulating the counterfactual equilibrium, assuming that the NSAs lead TMCZ and $\mathrm{O} 2$ to set their network qualities to maximize joint profits. Prices continue to be set by firms to maximize their own profits. Counterfactual marginal quantity costs $\tilde{c}_{i t}$ and counterfactual costs of providing network quality $\tilde{k}_{i t}^{J V}$ are derived based on the results of the baseline demand and cost estimation and these counterfactual costs are then used to solve for the corresponding equilibrium counterfactual prices, market shares and network quality.

If Vodafone's counterfactual costs are assumed to be unchanged in the absence of the NSA, a similar unrealistic equilibrium to the one presented in Section 5.3.3 emerges. As shown in Figure 5-4, for the case in which NSA parties are assumed to jointly choose qualities post Q1-2014, the resulting counterfactual download speeds are unrealistic. Predicted average changes in download speeds for O2, TMCZ and Vodafone are equal to $-54.6 \%,-70.6 \%$ and $169.7 \%$, respectively. This unrealistic result again shows that there exists no credible counterfactual scenario that features higher counterfactual costs of TMCZ and O2, without adjusting for a Vodafone's costs.

\footnotetext{
59 The difference in consumer surplus of $€ 111.1$ million per quarter results in a total difference of $€ 1.8$ billion over the four-year post-NSA period under investigation from Q1-2014 to Q4-2017 that is stated in the introduction.
} 
Figure 5-4: Counterfactual download speed (JV equilibrium, Vodafone costs unchanged)
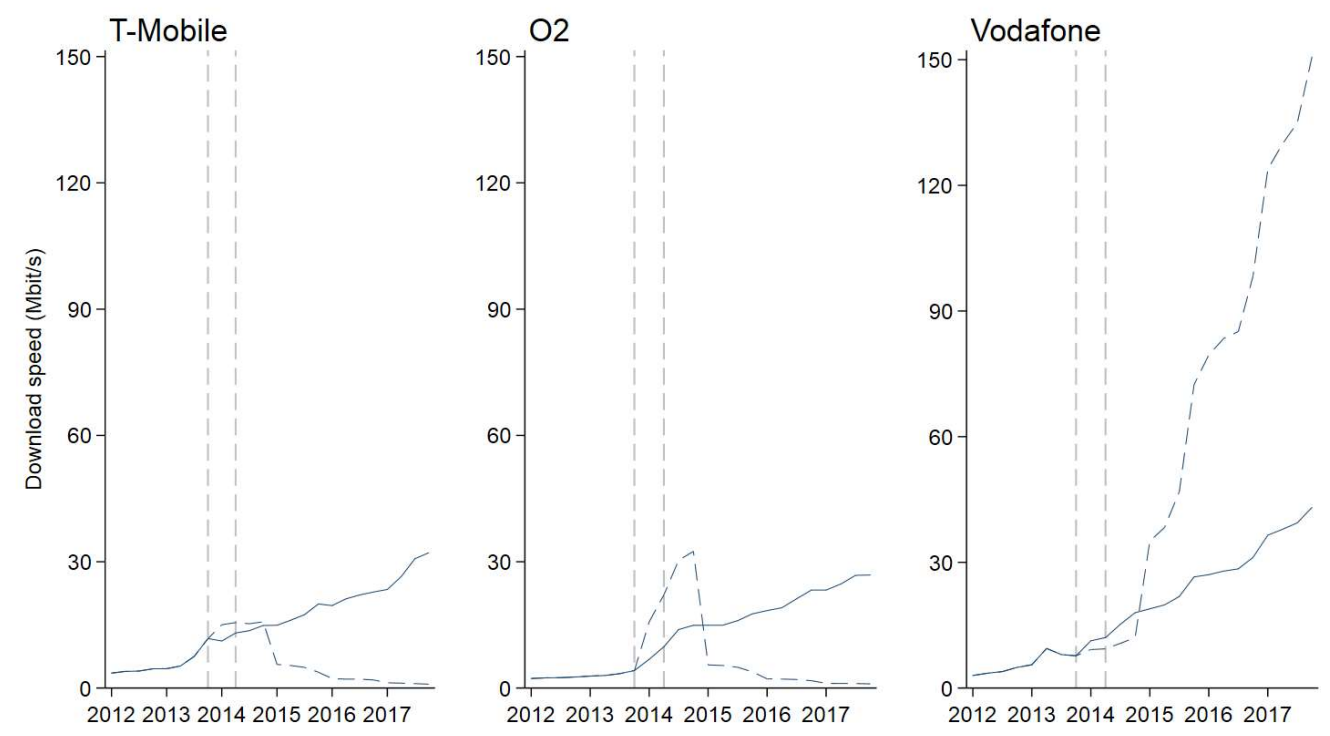

Observed speed

Counterfactual

Notes: The first dashed line refers to the signing date of $2 G / 3 G$ NSA, the second line to the signing date of the 4G/LTE NSA.

Source: Author's analysis.

In the JV equilibrium case, however, a realistic counterfactual equilibrium also does not emerge if Vodafone's counterfactual costs are adjusted. Analogous as in Section 5.3.3, the average increase in marginal costs of quantity $\tilde{c}_{i t}$ for TMCZ and $\mathrm{O} 2$ in the absence of the NSA is estimated to be $40.4 \%$ and $33.6 \%$, respectively and we assume that Vodafone's marginal costs of quantity would also have been 33\% higher in the absence of the NSAs. In addition, as in Section 5.3.3, an exogenous shock for the cost parameter of quality has been introduced for all operators. In the JV equilibrium case, however, the counterfactual equilibrium does not converge unless it is assumed that the quality costs parameters $\tilde{k}_{i t}^{J V}$ would have been much higher in the absence of the NSAs. ${ }^{60}$ Figure 5-5 displays the resulting counterfactual download speeds when the quality cost parameters are increased by a factor of 1.94. As it can be seen in the figure, these results are unrealistic, as the predicted average download speed provided for Vodafone is estimated to approach zero after Q1-2014.

These results provide empirical support for the fact that the Czech NSA is not organized as a joint venture agreement, meaning that $\mathrm{TMCZ}$ and $\mathrm{O} 2$ are not coordinating on the profit-maximizing choice of network quality. Instead because the NSA is organized as a geo-splitting agreement, it is not surprising that the structural model does not yield realistic results if this behavioral assumption is imposed in the MNOs in the Czech telecommunications market. The results together with the results of the Vuong test presented in Section 5.3.2 are taken as evidence that TMCZ and $\mathrm{O} 2$ are not jointly setting network quality and that the Czech mobile telecommunications market is characterized by a geo-split equilibrium.

\footnotetext{
60 The system of equations presented in Section 4.3 does not converge unless it is assumed that $\tilde{k}_{i t}^{J V}$ increases by a factor of at least 1.94 .
} 
Figure 5-5: Counterfactual download speed (JV equilibrium, similar cost increase)
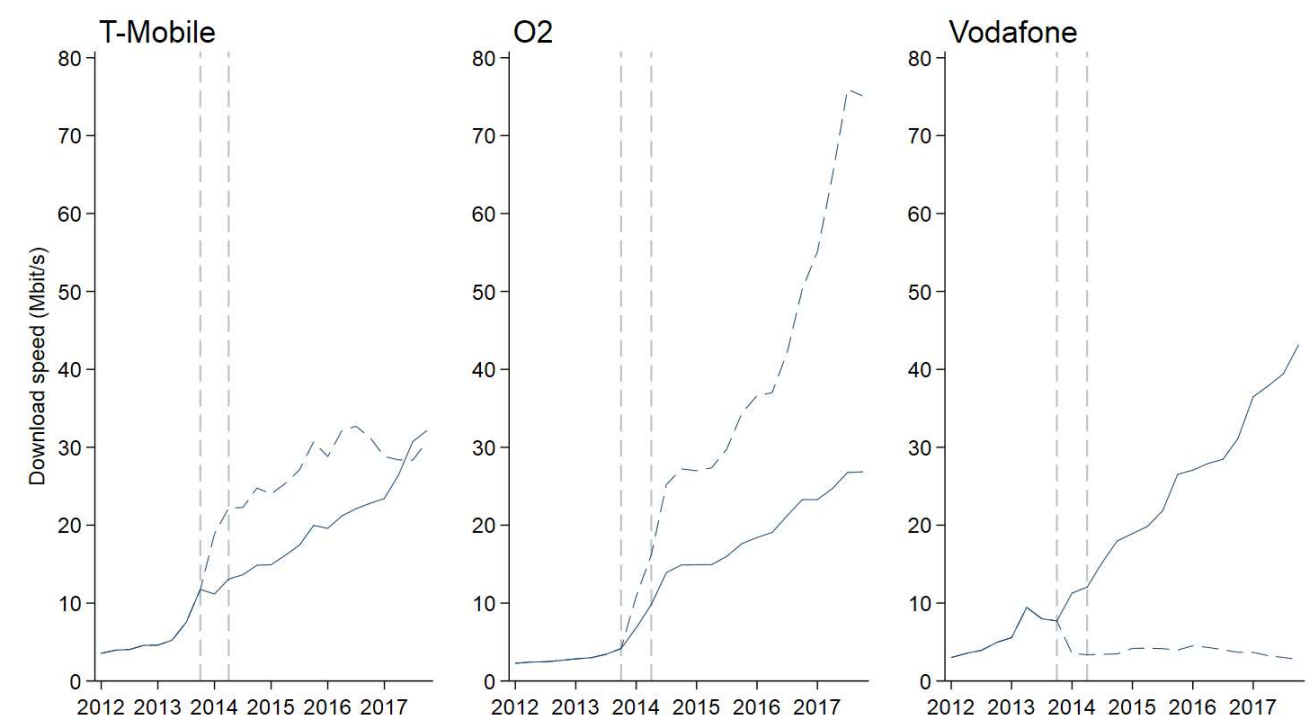

Observed speed

Counterfactual

Notes: The first dashed line refers to the signing date of 2G/3G NSA, the second line to the signing date of the 4G/LTE NSA.

Source: Author's analysis.

\section{Reduced-form evidence}

The results in Section 5 show that our structural model of network sharing, when applied to the mobile telecommunications industry in the Czech Republic, predicts that network sharing organized by a geosplitting agreement resulted in higher network quality. We assumed that network operators compete in network quality by directly choosing the optimal level of quality. This is a simplifying assumption as in reality network operators invest in network infrastructure, which consequently determines the level of network quality.

This section presents the results of a reduced-form analysis of network quality demonstrating that the finding of increased network quality after the implementation of the Czech NSA is not driven by the behavioral assumptions adopted in the structural model.

\subsection{Data}

As in the structural model, we use download speed to measure the actual customer experience of network quality. Data on download speed is obtained from the data provider Ookla, a leading mobile internet data provider. In contrast to the analysis in the structural model, the reduced-form analysis is based on disaggregated data at the district level, which is available on a quarterly basis by operator and access technology (2G, $3 \mathrm{G}$ and $4 \mathrm{G} / \mathrm{LTE}) .{ }^{61}$

Table 6-1 shows the difference in average download speed for each MNO in the Czech Republic before and after the implementation of the NSA. This simple temporal comparison shows that unsurprisingly customers' experienced download speed increased over time. TMCZ's average download speed

${ }^{61}$ The Ookla dataset is explained in more detail in Section 5.2.2. 
increased by $397.0 \%$ in the period after the NSA, while O2's and Vodafone's download speed increased by $709.2 \%$ and $499.3 \%$, respectively.

Table 6-1: Average download speed by operator and period

\begin{tabular}{|c|c|c|c|}
\hline \multirow[t]{2}{*}{ Operator } & \multirow[t]{2}{*}{ Period } & \multicolumn{2}{|c|}{ Czech Republic } \\
\hline & & -----Mbit/s----- & -----\%"----- \\
\hline \multirow{2}{*}{ TMCZ } & Before NSA & 5.71 & \multirow{2}{*}{397.0} \\
\hline & After NSA & 28.37 & \\
\hline \multirow{2}{*}{$\mathrm{O} 2$} & Before NSA & 2.75 & \multirow{2}{*}{709.2} \\
\hline & After NSA & 22.24 & \\
\hline \multirow{2}{*}{ Vodafone } & Before NSA & 5.45 & \multirow{2}{*}{499.3} \\
\hline & After NSA & 32.66 & \\
\hline
\end{tabular}

Notes: "Before NSA" corresponds to the average download speed in the period Q1-2011 - Q4-2013. "After NSA" corresponds to the period Q1-2014-Q2-2019.

Source: Author's analysis based on Ookla data.

Based on the descriptive statistics in Table 6-1, no conclusions on the causal effects of the NSA on quality can be drawn. To identify the effects of the NSA it is necessary to implement a regression analysis that allows controlling for different factors affecting the evolution of download speed over time.

\subsection{Estimation results}

To identify the impact of the NSAs on quality a before-after comparison by means of a regression analysis is performed. A dummy variable takes the value 0 before the implementation of the NSA and 1 when the NSA is signed (i.e. in Q1-2014), while other exogenous factors affecting network quality are controlled for. ${ }^{62}$

Actual download speed is contingent on numerous different factors. Network coverage, network capacity and the functionality of the RAN affect download speed and are under direct control of the network operators. Other factors such as the quality of internet ad content servers, population density, weather or topological characteristics can hardly be influenced by the operators. Finally, download speed crucially depends on network traffic, which is a function of the number of subscribers of an operator, price and other factors.

To account for these factors, we estimate the following equation: ${ }^{63}$

\footnotetext{
62 Applying a DID method is not possible here because we do not have data for a suitable control group that is unaffected by the NSA. Vodafone is not a suitable benchmark as it is a key competitor in the Czech market and strategically reacts to the NSA by also investing in network infrastructure. The districts of Prague and Brno are also not a suitable benchmark, even though they are not part of the NSA. The 4G/LTE technology was rolled out on a large scale by all MNOs in the years 2013 and 2014, starting in Prague and Brno. This timing coincides with the signing of the NSA. It is thus not possible to isolate the effects of the NSAs from the effect of the 4G/LTE technology rollout.

${ }^{63}$ As far as we know, there is no available article that provides a model of how effective network quality is determined. The specification is motivated by models of quality proposed by GSMA (2017).
} 


$$
\begin{aligned}
\ln \left(\text { speed }_{d, o, t}\right) & =\alpha+\beta_{1} * N S A_{2014 Q}+\beta_{2} * \text { capacity } 2 G_{d, o, t}+\beta_{3} * \text { capacity } 3 G_{d, o, t}+\beta_{4} \\
& * \text { capacity } 4 G_{d, o, t}+\beta_{5} * \text { unemployment }_{d, t} \beta_{6} * \ln \left(\text { ARPU }_{o, t-1}\right)+\beta_{7} \\
& * \ln \left(\text { subscribers }_{o, t-1}\right)+\beta_{8} * \ln \left(\text { data traffic }_{t-1}\right)+\text { Trend }_{t}+\text { Trend }^{2}{ }_{t}+D_{\text {area }} \\
& +D_{d}+D_{o}+\varepsilon_{d, o, t}
\end{aligned}
$$

where for district $d$, operator $o$ at time $t: \ln \left(\right.$ speed $\left._{d, o, t}\right)$ is the logarithm of quarterly average download speed; $N S A_{2014 Q 1}$ is a dummy variable equal to one post NSA (i.e. post Q4-2013) and zero otherwise; Capacity $2 G_{d, o, t}$, Capacity $3 G_{d, o, t}$, Capacity $4 G_{d, o, t}$ are the annual sums of deployed spectrum of the respective technology; Unemployment $t_{d, t}$ the annual unemployment rate; $\ln \left(A R P U_{o, t-1}\right)$ is the natural logarithm of the one-period lagged quarterly average revenue per user; $\ln \left(\right.$ Subscribers $\left._{o, t-1}\right)$ is the natural logarithm of the one-period lagged quarterly number of active subscribers; $\ln$ (data traffic d $_{t-1}$ ) is the natural logarithm of the one-period lagged total data traffic in the Czech Republic; Trend $_{t}$ is a linear trend variable; $D_{\text {area }}$ are area fixed effects (Prague $\&$ Brno, East, West); $D_{d}$ are district fixed effects and $D_{o}$ are operator fixed effects.

The variable of interest is $N S A$. The coefficient associated with this dummy variable measures the change in average download speed resulting from the NSAs after controlling for other factors affecting download speed. As explained above, download speed is contingent on the capacity that is available to the user. The variables Capacity 2G, Capacity 3G, and Capacity $4 G$ therefore control for per capita capacity available. ${ }^{64}$ Fixed effects are used to control for unobserved heterogeneity between areas, districts and operators. As the data on capacity by operator is available for 2012-2017 only, the estimation is limited to this time period..$^{65}$

The results of the regression analysis are presented in Table 6-2 below. The baseline specification, based on an NSA dummy that takes the value ' 1 ' post Q4-2013, is presented as specification (1). The results show that download speed increased after the implementation of the NSA, after controlling for major other substantial factors that affect download speed. ${ }^{66}$ The coefficient of the variable for $4 \mathrm{G}$ capacity is positive, which indicates that the introduction of the 4G/LTE technology had a positive effect on average download speed. The negative coefficient for $3 G$ capacity can be explained by refarming, i.e. the repurposing of frequency band. With the introduction of the $4 G / L T E$ technology, $3 \mathrm{G}$ spectrum decreased due to refarming to $4 \mathrm{G}$.

The positive coefficient for ARPU indicates a higher willingness to pay for higher network quality. The negative coefficient for the total number of active subscribers captures the effect of network congestion, which negatively influences network quality. The fact that the trend variable is statistically significant indicates that there are factors besides the roll out of the 4G/LTE technology that positively affect network quality. One explanation could be that more consumers preferred a tariff that enabled high speed internet, or that more consumers switched to handsets capable of higher speeds. The squared trend variable captures nonlinear patterns in the evolution of download speed. Finally, the

\footnotetext{
${ }^{64}$ Per capita capacities are calculated as the sum of total spectrum deployed by technology, operator and district, divided by the total population of the respective district.

65 Standard errors are clustered at the operator-district level to account for autocorrelation and heteroskedasticity.

${ }^{66}$ The effect of the NSA dummy variable is calculated using the "Kennedy transformation" and presented in the last row of Table 6-2. Kennedy (1981) showed that a consistent and unbiased estimator is given by $[\exp (\widehat{\delta}) / \exp (0.5(\widehat{V}(\widehat{\delta})))]-1$ with $\widehat{\delta}$ the OLS estimator of $\delta$ and $\widehat{V}(\widehat{\delta})$ its estimated variance.
} 
positive operator fixed effects for $\mathrm{O} 2$ and TMCZ indicate that the Parties to the NSA on average provide a higher download speed than Vodafone. The area fixed effects indicate that average download speed in the East and West is lower than in the cities of Prague and Brno, which serve as the baseline areas.

Table 6-2: Estimation results

\begin{tabular}{|c|c|c|c|c|c|c|c|}
\hline $\ln ($ Speed $)$ & (1) & (2) & (3) & (4) & $(5)$ & (6) & (7) \\
\hline NSA & $\begin{array}{l}0.197 * * * \\
(0.030)\end{array}$ & $\begin{array}{l}0.191 * * * \\
(0.030)\end{array}$ & $\begin{array}{l}0.302 * * * \\
(0.029)\end{array}$ & $\begin{array}{l}0.187 * * * \\
(0.030)\end{array}$ & $\begin{array}{l}0.257 * * * \\
(0.027)\end{array}$ & $\begin{array}{l}0.203 * * * \\
(0.030)\end{array}$ & $\begin{array}{l}0.232 * * * \\
(0.031)\end{array}$ \\
\hline 2G spectrum (Mhz) & $\begin{array}{l}61.977 \\
(41.919)\end{array}$ & $\begin{array}{l}81.898^{* *} \\
(39.531)\end{array}$ & $\begin{array}{l}79.226^{*} \\
(40.866)\end{array}$ & $\begin{array}{l}146.187 * * * \\
(40.037)\end{array}$ & $\begin{array}{l}154.847^{* * *} \\
(42.256)\end{array}$ & $\begin{array}{l}49.71 \\
(41.220)\end{array}$ & $\begin{array}{l}68.483 \\
(41.685)\end{array}$ \\
\hline 3G spectrum (Mhz) & $\begin{array}{l}-19.099 * * * \\
(5.523)\end{array}$ & $\begin{array}{l}-26.794 * * * \\
(8.353)\end{array}$ & $\begin{array}{l}-19.612 * * * \\
(5.532)\end{array}$ & $\begin{array}{l}-19.652 * * * \\
(5.671)\end{array}$ & $\begin{array}{l}-16.785^{* * *} \\
(5.912)\end{array}$ & $\begin{array}{l}-19.093 * * * \\
(5.559)\end{array}$ & $\begin{array}{l}-19.503^{* * *} \\
(5.520)\end{array}$ \\
\hline 4G spectrum (Mhz) & $\begin{array}{l}15.755^{* * *} \\
(1.967)\end{array}$ & $\begin{array}{l}12.403 * * * \\
(2.112)\end{array}$ & $\begin{array}{l}14.075^{* * *} \\
(1.908)\end{array}$ & $\begin{array}{l}14.078 * * * \\
(1.916)\end{array}$ & $\begin{array}{l}11.029 * * * \\
(1.955)\end{array}$ & $\begin{array}{l}16.505^{* * *} \\
(1.889)\end{array}$ & $\begin{array}{l}16.136^{* * *} \\
(1.949)\end{array}$ \\
\hline $\ln (\mathrm{ARPU})$, lagged & $\begin{array}{l}0.885^{* * *} \\
(0.103)\end{array}$ & $\begin{array}{l}0.820^{* * *} \\
(0.103)\end{array}$ & $\begin{array}{l}0.374 * * * \\
(0.114)\end{array}$ & $\begin{array}{l}0.509 * * * \\
(0.092)\end{array}$ & $\begin{array}{l}-0.885^{* * *} \\
(0.088)\end{array}$ & $\begin{array}{l}0.901 * * * \\
(0.103)\end{array}$ & $\begin{array}{l}0.944 * * * \\
(0.106)\end{array}$ \\
\hline $\begin{array}{l}\ln (\text { Subscribers), } \\
\text { lagged }\end{array}$ & $\begin{array}{l}-1.313^{* * *} \\
(0.313)\end{array}$ & $\begin{array}{l}-1.334 * * * \\
(0.313)\end{array}$ & $\begin{array}{l}-1.138^{* * *} \\
(0.315)\end{array}$ & $\begin{array}{l}-1.486^{* * *} \\
(0.317)\end{array}$ & $\begin{array}{l}-1.228^{* * *} \\
(0.312)\end{array}$ & $\begin{array}{l}-1.326^{* * *} \\
(0.313)\end{array}$ & $\begin{array}{l}-1.334 * * * \\
(0.314)\end{array}$ \\
\hline $\begin{array}{l}\ln (\text { Total data } \\
\text { traffic), lagged }\end{array}$ & $\begin{array}{l}0.309^{* * *} \\
(0.116)\end{array}$ & $\begin{array}{l}0.344 * * * \\
(0.114)\end{array}$ & $\begin{array}{l}0.332 * * * \\
(0.114)\end{array}$ & $\begin{array}{l}-0.796^{* * *} \\
(0.114)\end{array}$ & $\begin{array}{l}0.642 * * * \\
(0.028)\end{array}$ & $\begin{array}{l}0.320^{* * *} \\
(0.116)\end{array}$ & $\begin{array}{l}0.387 * * * \\
(0.111)\end{array}$ \\
\hline Unemployment rate & $\begin{array}{l}-0.037 * * * \\
(0.011)\end{array}$ & $\begin{array}{l}-0.040^{* * *} \\
(0.010)\end{array}$ & $\begin{array}{l}-0.030^{* * *} \\
(0.010)\end{array}$ & $\begin{array}{l}-0.026^{* *} \\
(0.011)\end{array}$ & $\begin{array}{l}-0.003 \\
(0.011)\end{array}$ & $\begin{array}{l}-0.032 * * * \\
(0.012)\end{array}$ & \\
\hline \multicolumn{8}{|l|}{ Operator FE: } \\
\hline $\mathrm{O} 2$ & $\begin{array}{l}0.401 * * \\
(0.175)\end{array}$ & & $\begin{array}{l}0.278 \\
(0.177)\end{array}$ & $\begin{array}{l}0.452 * * \\
(0.177)\end{array}$ & $\begin{array}{l}0.223 \\
(0.173)\end{array}$ & $\begin{array}{l}0.410^{* *} \\
(0.175)\end{array}$ & $\begin{array}{l}0.414 * * \\
(0.175)\end{array}$ \\
\hline TMCZ & $\begin{array}{l}0.574 * * * \\
(0.183)\end{array}$ & & $\begin{array}{l}0.438^{* *} \\
(0.186)\end{array}$ & $\begin{array}{l}0.623 * * * \\
(0.186)\end{array}$ & $\begin{array}{l}0.356^{*} \\
(0.181)\end{array}$ & $\begin{array}{l}0.582 * * * \\
(0.184)\end{array}$ & $\begin{array}{l}0.589 * * * \\
(0.183)\end{array}$ \\
\hline \multicolumn{8}{|l|}{ Area FE: } \\
\hline East & $\begin{array}{l}-0.445^{* * *} \\
(0.050)\end{array}$ & & $\begin{array}{l}-0.458^{* * *} \\
(0.051)\end{array}$ & $\begin{array}{l}-0.469^{* * *} \\
(0.049)\end{array}$ & $\begin{array}{l}-0.463^{* * *} \\
(0.052)\end{array}$ & $\begin{array}{l}-7.432 \\
(4.650)\end{array}$ & $\begin{array}{l}-0.313 \\
(0.440)\end{array}$ \\
\hline West & $\begin{array}{l}-0.278^{* * *} \\
(0.059)\end{array}$ & & $\begin{array}{l}-0.311^{* * *} \\
(0.058)\end{array}$ & $\begin{array}{l}-0.318^{* * * *} \\
(0.059)\end{array}$ & $\begin{array}{l}-0.381 * * * \\
(0.060)\end{array}$ & $\begin{array}{l}-7.169 \\
(4.588)\end{array}$ & $\begin{array}{l}-0.226 \\
(0.451)\end{array}$ \\
\hline Trend & $\begin{array}{l}0.189 * * * \\
(0.016)\end{array}$ & $\begin{array}{l}0.184 * * * \\
(0.015)\end{array}$ & $\begin{array}{l}0.142 * * * \\
(0.017)\end{array}$ & $\begin{array}{l}0.204^{* * *} \\
(0.016)\end{array}$ & & $\begin{array}{l}0.188^{* * *} \\
(0.016)\end{array}$ & $\begin{array}{l}0.181 * * * \\
(0.015)\end{array}$ \\
\hline Trend $^{2}$ & $\begin{array}{l}-0.005^{* * *} \\
(0.000)\end{array}$ & $\begin{array}{l}-0.005^{* * *} \\
(0.000)\end{array}$ & $\begin{array}{l}-0.004 * * * \\
(0.000)\end{array}$ & & & $\begin{array}{l}-0.005^{* * *} \\
(0.000)\end{array}$ & $\begin{array}{l}-0.005^{* * *} \\
(0.000)\end{array}$ \\
\hline Population density & & & & & & $\begin{array}{l}-0.003 \\
(0.002)\end{array}$ & \\
\hline GDP per capita & & & & & & & $\begin{array}{l}0.000 \\
(0.000)\end{array}$ \\
\hline Constant & $\begin{array}{l}10.675^{*} \\
(5.789)\end{array}$ & $\begin{array}{l}10.595^{*} \\
(5.914)\end{array}$ & $\begin{array}{l}9.660^{*} \\
(5.775)\end{array}$ & $\begin{array}{l}38.820^{* * *} \\
(5.634)\end{array}$ & $\begin{array}{l}9.337^{*} \\
(4.509)\end{array}$ & $\begin{array}{l}17.732 * * \\
(7.542)\end{array}$ & $\begin{array}{l}8.658^{*} \\
(5.776)\end{array}$ \\
\hline Observations & 5540 & 5540 & 5540 & 5540 & 5540 & 5540 & 5540 \\
\hline Adj. $R^{2}$ & 0.851 & 0.861 & 0.856 & 0.847 & 0.839 & 0.851 & 0.851 \\
\hline District fixed effects & Yes & No & Yes & Yes & Yes & Yes & Yes \\
\hline District-operator fix & No & Yes & No & No & No & No & No \\
\hline NSA effect & $21.7 \%$ & $21.03 \%$ & $35.15 \%$ & $20.55 \%$ & $29.22 \%$ & $22.41 \%$ & $26.06 \%$ \\
\hline
\end{tabular}

Notes: Clustered standard errors in parentheses. ${ }^{*} \mathrm{p}<0.1,{ }^{* *} \mathrm{p}<0.05,{ }^{* * *} \mathrm{p}<0.01$. Operator fixed effects are relative to O2, the omitted MNO.

Source: Authors' calculation.

Specifications (2) to (7) present robustness checks of the baseline specification. All specifications show that download speed increased after the implementation of the NSA, independently of the introduced changes in the specification of the econometric model. Specification (2) presents a fixed effects regression that uses the full set of district-operator fixed effects, instead of separately controlling for operator and area fixed effects. Specification (3) assumes that the effect of the NSA as explained by the NSA dummy starts post Q2-2014 instead of post Q4-2013, to capture the starting point of the 
4G/LTE NSA instead of the 2G/3G NSA. The results show that the estimated NSA effect is even higher in this case, which is unsurprising since the 4G/LTE NSA enabled the Parties to extend their 4G/LTE coverage much faster than what had been possible without the NSAs. Specification (4) and (5) present the results after removing the squared trend and the trend variable from the regression model, respectively. The fact that both trend variables are statistically significant in specification (1) indicated that above and beyond the included control variables there are factors affecting download speed that are not captured by the model. This finding is confirmed as in specification (5), without the inclusion of trend variables, the NSA dummy seems to capture some of these factors, resulting in a higher estimated effect of the NSA. Finally, specifications (6) and (7) present the results after including additional control variables of population density and the Czech unemployment rate, respectively. Both variables are not statistically significant, suggesting that their effect is already captured by the other explanatory variables.

To summarize, the results of the reduced-form analysis on network quality confirm the results of the structural model that the introduction of the NSA resulted in an increase in download speed for all mobile network operators in the Czech Republic. The analysis controls for the effects of the main driving forces of network quality and therefore provides direct evidence that the increase in download speed after the introduction of the NSA is causally linked to the NSA.

\section{Structural model: Robustness checks}

\subsection{Robustness checks of the demand estimation}

This section presents the robustness checks performed to validate the correctness of results obtained by the baseline estimation, presented in Section 5 .

\subsubsection{Different choice of instruments}

Table 7-1 contains the estimates of the baseline demand specification but considering different subsets of instruments. As seen in the table, results are robust to different specifications. The only instrument that needs to be considered across all specifications is the lag of the market share within group, as this variable seems to be required in order to properly identify the estimated value of $\sigma$. Indeed, when removing this variable from the set of instruments, the estimated value of $\sigma$ becomes non-significant, higher than one or negative in most of the specifications and hence does not satisfy basic economic principles. ${ }^{67}$

\footnotetext{
${ }^{67}$ In addition, when removing the lag of market share within group from specification (4), the estimated ownprice elasticities become on average lower than one, which results in predicted marginal costs lower than zero.
} 
Table 7-1: Demand estimates with subset of instruments

\begin{tabular}{|c|c|c|c|c|c|c|}
\hline \multirow[b]{4}{*}{ ln(Market share) } & (1) & (2) & (3) & (4) & (5) & (6) \\
\hline & \multicolumn{6}{|c|}{ Change in instruments } \\
\hline & \multicolumn{3}{|c|}{ (A) } & \multicolumn{3}{|c|}{ (B) } \\
\hline & Base & $\begin{array}{c}\text { No own } \\
\text { download } \\
\text { speed }\end{array}$ & No own price & Base & $\begin{array}{l}\text { No prices in } \\
\text { Slovakia }\end{array}$ & No own price \\
\hline Price $(-\alpha)$ & $\begin{array}{l}-0.0127 * * * \\
(-12.49)\end{array}$ & $\begin{array}{l}-0.0131 * * * \\
(-12.15)\end{array}$ & $\begin{array}{l}-0.0129 * * * \\
(-10.66)\end{array}$ & $\begin{array}{l}-0.0127^{* * *} \\
(-12.41)\end{array}$ & $\begin{array}{l}-0.0127 * * * \\
(-12.77)\end{array}$ & $\begin{array}{l}-0.0142^{* * *} \\
(-7.20)\end{array}$ \\
\hline Avg. download speed ( $\beta$ ) & $\begin{array}{l}0.00837 * * * \\
(11.75)\end{array}$ & $\begin{array}{l}0.00765^{* * *} \\
(8.38)\end{array}$ & $\begin{array}{l}0.00760^{* * *} \\
(8.43)\end{array}$ & $\begin{array}{l}0.00850^{* * * *} \\
(11.71)\end{array}$ & $\begin{array}{l}0.00848^{* * *} \\
(12.12)\end{array}$ & $\begin{array}{l}0.00791^{* * *} \\
(9.16)\end{array}$ \\
\hline Market share within group $(\sigma)$ & $\begin{array}{l}0.830 * * * \\
(5.26)\end{array}$ & $\begin{array}{l}0.847^{* * *} \\
(5.20)\end{array}$ & $\begin{array}{l}0.856^{* * *} \\
(5.39)\end{array}$ & $\begin{array}{l}0.821 * * * \\
(5.12)\end{array}$ & $\begin{array}{l}0.833^{* * *} \\
(5.41)\end{array}$ & $\begin{array}{l}0.887^{* * * *} \\
(5.83)\end{array}$ \\
\hline 4G spectrum $(\mathrm{MHz})$ & $\begin{array}{l}0.00268^{* * *} \\
(4.16)\end{array}$ & $\begin{array}{l}0.00326^{* * *} \\
(3.87)\end{array}$ & $\begin{array}{l}0.00340^{* * *} \\
(4.08)\end{array}$ & $\begin{array}{l}0.00255^{* * * *} \\
(4.01)\end{array}$ & $\begin{array}{l}0.00256^{* * *} \\
(4.13)\end{array}$ & $\begin{array}{l}0.00258^{* * * *} \\
(3.72)\end{array}$ \\
\hline \multicolumn{7}{|l|}{ Operator FE: } \\
\hline TMCZ & $\begin{array}{l}-0.0321^{* * *} \\
(-3.02)\end{array}$ & $\begin{array}{l}-0.0332^{* * *} \\
(-3.15)\end{array}$ & $\begin{array}{l}-0.0335^{* * *} \\
(-3.17)\end{array}$ & $\begin{array}{l}-0.0318^{* * *} \\
(-2.99)\end{array}$ & $\begin{array}{l}-0.0321 * * * \\
(-3.04)\end{array}$ & $\begin{array}{l}-0.0338^{* * *} \\
(-3.22)\end{array}$ \\
\hline Vodafone & $\begin{array}{l}-0.0989 \\
(-1.09)\end{array}$ & $\begin{array}{l}-0.0823 \\
(-0.87)\end{array}$ & $\begin{array}{l}-0.0771 \\
(-0.84)\end{array}$ & $\begin{array}{l}-0.105 \\
(-1.14)\end{array}$ & $\begin{array}{l}-0.0985 \\
(-1.11)\end{array}$ & $\begin{array}{l}-0.0633 \\
(-0.72)\end{array}$ \\
\hline Constant & $\begin{array}{l}1.498^{* * *} \\
(8.42)\end{array}$ & $\begin{array}{l}1.535^{* * *} \\
(8.38)\end{array}$ & $\begin{array}{l}1.535^{* * *} \\
(8.40)\end{array}$ & $\begin{array}{l}1.488^{* * * *} \\
(8.20)\end{array}$ & $\begin{array}{l}1.501 * * * \\
(8.66)\end{array}$ & $\begin{array}{l}1.613^{* * *} \\
(8.98)\end{array}$ \\
\hline Observations & 72 & 72 & 72 & 72 & 72 & 72 \\
\hline Adj. $R^{2}$ & 0.988 & 0.988 & 0.988 & 0.988 & 0.988 & 0.987 \\
\hline Over-identification test (p-value) & 0.141 & 0.192 & 0.301 & 0.0881 & 0.0265 & 0.00773 \\
\hline Elasticities & & & & & & \\
\hline Own price elasticity & -1.782 & -2.040 & -2.131 & -1.688 & -1.815 & -2.974 \\
\hline Cross price elasticity & 0.833 & 0.959 & 1.004 & 0.787 & 0.850 & 1.416 \\
\hline Instruments & & & & & & \\
\hline Lags of own price & Yes & Yes & No & Yes & Yes & No \\
\hline Lags of own (within group) market share & Yes & Yes & Yes & Yes & Yes & Yes \\
\hline Lag of own download speed & Yes & No & No & Yes & Yes & Yes \\
\hline Lags of prices of operators in Slovakia & Yes & Yes & Yes & Yes & No & No \\
\hline Lags of download speeds of competitors & No & No & No & Yes & Yes & Yes \\
\hline
\end{tabular}

Notes: $\mathrm{t}$-values in parentheses. ${ }^{*} \mathrm{p}<0.1,{ }^{* *} \mathrm{p}<0.05,{ }^{* * *} \mathrm{p}<0.01$. In subtable (B), the lags of download speeds of competitors have been included as instruments. Operator fixed effects are relative to $\mathrm{O} 2$, the omitted MNO. Source: Authors' calculation.

\subsubsection{Alternative measure of $4 \mathrm{G}$ coverage}

This baseline specification is replicated but using the number of resource blocks as control for $4 \mathrm{G}$ coverage in Table 7-2. The resulting estimated coefficients for the relevant parameters of the model remain within similar order of magnitudes compared to the baseline model.

In this case, however, in specifications (1), (2) and (3) one cannot reject the null hypothesis that the instruments are valid, but only either at the $1 \%$ or $5 \%$ levels. In specifications (4) to (6) the nullhypothesis of the validity of the instruments is rejected. 
Table 7-2: Demand estimates with other measures of 4G coverage (resource blocks)

\begin{tabular}{|c|c|c|c|c|c|c|}
\hline \multirow[b]{4}{*}{ In(Market share) } & (1) & (2) & (3) & (4) & (5) & (6) \\
\hline & \multicolumn{6}{|c|}{ Change in instruments } \\
\hline & \multicolumn{3}{|c|}{ (A) } & \multicolumn{3}{|c|}{ (B) } \\
\hline & Base & $\begin{array}{c}\text { No own } \\
\text { download } \\
\text { speed }\end{array}$ & No own price & Base & $\begin{array}{c}\text { No prices in } \\
\text { Slovakia }\end{array}$ & No own price \\
\hline Price $(-\alpha)$ & $\begin{array}{l}-0.0130 * * * \\
(-11.71)\end{array}$ & $\begin{array}{l}-0.0138^{* * *} \\
(-11.20)\end{array}$ & $\begin{array}{l}-0.0136^{* * *} \\
(-10.38)\end{array}$ & $\begin{array}{l}-0.0130 * * * \\
(-11.52)\end{array}$ & $\begin{array}{l}-0.0130 * * * \\
(-11.97)\end{array}$ & $\begin{array}{l}-0.0169^{* * * *} \\
(-6.78)\end{array}$ \\
\hline Avg. download speed $(\beta)$ & $\begin{array}{l}0.00791 * * * \\
(7.54)\end{array}$ & $\begin{array}{l}0.00581^{* * * *} \\
(3.54)\end{array}$ & $\begin{array}{l}0.00503 * * * \\
(3.05)\end{array}$ & $\begin{array}{l}0.00823 * * * \\
(7.40)\end{array}$ & $\begin{array}{l}0.00821^{* * *} \\
(7.73)\end{array}$ & $\begin{array}{l}0.00590 * * * \\
(3.35)\end{array}$ \\
\hline Market share within group $(\sigma)$ & $\begin{array}{l}0.781 * * * \\
(4.58)\end{array}$ & $\begin{array}{l}0.805^{* * *} \\
(4.46)\end{array}$ & $\begin{array}{l}0.820^{* * * *} \\
(4.56)\end{array}$ & $\begin{array}{l}0.762 * * * \\
(4.41)\end{array}$ & $\begin{array}{l}0.771 * * * \\
(4.59)\end{array}$ & $\begin{array}{l}0.915^{* * * *} \\
(4.56)\end{array}$ \\
\hline $4 \mathrm{G}$ resource blocks & $\begin{array}{l}0.0000477 * * * \\
(2.90)\end{array}$ & $\begin{array}{l}0.0000857 * * * \\
(2.94)\end{array}$ & $\begin{array}{l}0.000102 * * * \\
(3.30)\end{array}$ & $\begin{array}{l}0.0000414^{* *} \\
(2.41)\end{array}$ & $\begin{array}{l}0.0000418^{* *} \\
(2.49)\end{array}$ & $\begin{array}{l}0.0000625 * * \\
(2.51)\end{array}$ \\
\hline \multicolumn{7}{|l|}{ Operator FE: } \\
\hline TMCZ & $\begin{array}{l}-0.0294 * * * \\
(-2.79)\end{array}$ & $\begin{array}{l}-0.0318^{* * * *} \\
(-3.07)\end{array}$ & $\begin{array}{l}-0.0329 * * * \\
(-3.12)\end{array}$ & $\begin{array}{l}-0.0286^{* * * *} \\
(-2.72)\end{array}$ & $\begin{array}{l}-0.0289 * * * \\
(-2.74)\end{array}$ & $\begin{array}{l}-0.0344 * * * \\
(-2.95)\end{array}$ \\
\hline Vodafone & $\begin{array}{l}-0.136 \\
(-1.37)\end{array}$ & $\begin{array}{l}-0.112 \\
(-1.07)\end{array}$ & $\begin{array}{l}-0.101 \\
(-0.98)\end{array}$ & $\begin{array}{l}-0.148 \\
(-1.47)\end{array}$ & $\begin{array}{l}-0.143 \\
(-1.46)\end{array}$ & $\begin{array}{l}-0.0457 \\
(-0.39)\end{array}$ \\
\hline Constant & $\begin{array}{l}1.471 * * * \\
(7.61)\end{array}$ & $\begin{array}{l}1.533 * * * \\
(7.62)\end{array}$ & $\begin{array}{l}1.547^{* * * *} \\
(7.74)\end{array}$ & $\begin{array}{l}1.448^{* * * *} \\
(7.36)\end{array}$ & $\begin{array}{l}1.458 * * * \\
(7.66)\end{array}$ & $\begin{array}{l}1.753^{* * * *} \\
(7.33)\end{array}$ \\
\hline Observations & 72 & 72 & 72 & 72 & 72 & 72 \\
\hline Adj. $R^{2}$ & 0.987 & 0.986 & 0.986 & 0.987 & 0.987 & 0.983 \\
\hline Over-identification test ( $\mathrm{p}$-value) & 0.0269 & 0.0235 & 0.0787 & 0.0192 & 0.00366 & 0.00600 \\
\hline Elasticities: & & & & & & \\
\hline Own price elasticity & -1.425 & -1.688 & -1.813 & -1.306 & -1.360 & -4.682 \\
\hline Cross price elasticity & 0.656 & 0.783 & 0.845 & 0.597 & 0.624 & 2.249 \\
\hline Instruments: & & & & & & \\
\hline Lags of own price & Yes & Yes & No & Yes & Yes & No \\
\hline Lags of own (within group) market share & Yes & Yes & Yes & Yes & Yes & Yes \\
\hline Lag of own download speed & Yes & No & No & Yes & Yes & Yes \\
\hline Lags of prices of operators in Slovakia & Yes & Yes & Yes & Yes & No & No \\
\hline Lags of download speeds of competitors & No & No & No & Yes & Yes & Yes \\
\hline
\end{tabular}

Notes: t-values in parentheses. ${ }^{*} p<0.1, * * p<0.05, * * * p<0.01$. In subtable (B), the lags of download speeds of competitors have been included as instruments. Operator fixed effects are relative to $\mathrm{O} 2$, the omitted MNO.

Source: Authors' calculation.

\subsection{3. $2 \mathrm{G}$ and $3 \mathrm{G}$ coverage}

Measures of $2 \mathrm{G}$ and $3 \mathrm{G}$ coverage are included in the set of explanatory variables (in terms of spectrum deployed). As shown in Table 7-3, the coefficient associated with $2 \mathrm{G}$ coverage is not significantly different from zero. When controlling for 3G coverage, however, the coefficient associated with 4G coverage becomes non-significant (and the $3 \mathrm{G}$ coefficient is only significant at the $10 \%$ level). For this reason, the baseline demand specification only considers $4 G$ coverage as explanatory variable, and the coefficient is significantly different from zero at all significance levels. 


\begin{tabular}{|c|c|c|c|}
\hline In(Market share) & $\begin{array}{c}\text { (1) } \\
\text { Base }\end{array}$ & $\begin{array}{c}(2) \\
\text { No } 2 G \\
\text { spectrum }\end{array}$ & $\begin{array}{c}(3) \\
\text { No } 2 G / 3 G \\
\text { spectrum }\end{array}$ \\
\hline Price $(-\alpha)$ & $\begin{array}{l}-0.0127^{* * *} \\
(-12.49)\end{array}$ & $\begin{array}{l}-0.0121 * * * \\
(-12.37)\end{array}$ & $\begin{array}{l}-0.0120 * * * \\
(-11.58)\end{array}$ \\
\hline Avg. download speed $(\beta)$ & $\begin{array}{l}0.00837 * * * \\
(11.75)\end{array}$ & $\begin{array}{l}0.00875^{* * *} \\
(12.38)\end{array}$ & $\begin{array}{l}0.00886^{* * *} \\
(11.99)\end{array}$ \\
\hline Market share within group $(\sigma)$ & $\begin{array}{l}0.830^{* * *} \\
(5.26)\end{array}$ & $\begin{array}{l}0.903^{* * *} \\
(6.34)\end{array}$ & $\begin{array}{l}0.884^{* * * *} \\
(6.10)\end{array}$ \\
\hline $2 \mathrm{G}$ spectrum $(\mathrm{MHz})$ & & & $\begin{array}{l}-0.0220 \\
(-0.60)\end{array}$ \\
\hline $3 \mathrm{G}$ spectrum $(\mathrm{MHz})$ & & $\begin{array}{l}0.0158^{* *} \\
(2.07)\end{array}$ & $\begin{array}{l}0.0180^{* *} \\
(2.05)\end{array}$ \\
\hline 4G spectrum $(\mathrm{MHz})$ & $\begin{array}{l}0.00268^{* * *} \\
(4.16)\end{array}$ & $\begin{array}{l}0.000766 \\
(0.78)\end{array}$ & $\begin{array}{l}0.000724 \\
(0.74)\end{array}$ \\
\hline \multicolumn{4}{|l|}{ Operator FE: } \\
\hline TMCZ & $\begin{array}{l}-0.0321 * * * \\
(-3.02)\end{array}$ & $\begin{array}{l}-0.0422^{* * *} \\
(-3.55)\end{array}$ & $\begin{array}{l}-0.0429 * * * \\
(-3.51)\end{array}$ \\
\hline Vodafone & $\begin{array}{l}-0.0989 \\
(-1.09)\end{array}$ & $\begin{array}{l}-0.000281 \\
(-0.00)\end{array}$ & $\begin{array}{l}-0.00692 \\
(-0.08)\end{array}$ \\
\hline Constant & $\begin{array}{l}1.498^{* * *} \\
(8.42)\end{array}$ & $\begin{array}{l}1.464 * * * \\
(8.91)\end{array}$ & $\begin{array}{l}1.444^{* * *} \\
(8.64)\end{array}$ \\
\hline Observations & 72 & 72 & 72 \\
\hline Adj. $R^{2}$ & 0.988 & 0.988 & 0.988 \\
\hline Over-identification test (p-value) & 0.141 & 0.246 & 0.283 \\
\hline Elasticities & & & \\
\hline Own price elasticity & -1.782 & -2.962 & -2.457 \\
\hline Cross price elasticity & 0.833 & 1.418 & 1.169 \\
\hline Instruments & & & \\
\hline Lags of own price & Yes & Yes & Yes \\
\hline Lags of own (within group) market share & Yes & Yes & Yes \\
\hline Lag of own download speed & Yes & Yes & Yes \\
\hline Lags of prices of operators in Slovakia & Yes & Yes & Yes \\
\hline Lags of download speeds of competitors & No & No & No \\
\hline
\end{tabular}

Notes: $\mathrm{t}$-values in parentheses. ${ }^{*} \mathrm{p}<0.1,{ }^{* *} \mathrm{p}<0.05,{ }^{* *} \mathrm{p}<0.01$. Operator fixed effects are relative to 02 , the omitted MNO.

Source: Authors' calculation.

\subsubsection{Adding year fixed effects}

Adding year fixed effects on the set of explanatory variables allows replicating the findings. As can be seen in Table 7-4, none of the coefficients of the year fixed effects are significantly different from zero, hence their inclusion in the model is not justified. 
Table 7-4: Demand estimates with year fixed effects

\begin{tabular}{|c|c|c|c|c|c|c|}
\hline \multirow[b]{4}{*}{ In(Market share) } & (1) & (2) & (3) & (4) & (5) & (6) \\
\hline & \multicolumn{6}{|c|}{ Change in instruments } \\
\hline & \multicolumn{3}{|c|}{ (A) } & \multicolumn{3}{|c|}{ (B) } \\
\hline & Base & $\begin{array}{c}\text { No own } \\
\text { download } \\
\text { speed }\end{array}$ & No own price & Base & $\begin{array}{l}\text { No prices in } \\
\text { Slovakia }\end{array}$ & No own price \\
\hline Price $(-\alpha)$ & $\begin{array}{l}-0.00978 * * * \\
(-2.52)\end{array}$ & $\begin{array}{l}-0.0131 * * * \\
(-2.82)\end{array}$ & $\begin{array}{l}-0.00575 \\
(-0.69)\end{array}$ & $\begin{array}{l}-0.0105^{* * *} \\
(-2.92)\end{array}$ & $\begin{array}{l}-0.0120 * * * \\
(-3.34)\end{array}$ & $\begin{array}{l}-0.00416 \\
(-0.46)\end{array}$ \\
\hline Avg. download speed $(\beta)$ & $\begin{array}{l}0.0113^{* * *} \\
(7.65)\end{array}$ & $\begin{array}{l}0.00429 \\
(1.04)\end{array}$ & $\begin{array}{l}-0.00113 \\
(-0.18)\end{array}$ & $\begin{array}{l}0.0123^{* * * *} \\
(8.14)\end{array}$ & $\begin{array}{l}0.0131^{* * * *} \\
(8.47)\end{array}$ & $\begin{array}{l}0.0125^{* * *} \\
(7.69)\end{array}$ \\
\hline Market share within group $(\sigma)$ & $\begin{array}{l}0.769 * * * \\
(5.36)\end{array}$ & $\begin{array}{l}0.877 * * * \\
(5.18)\end{array}$ & $\begin{array}{l}0.998 * * * \\
(4.73)\end{array}$ & $\begin{array}{l}0.742 * * * \\
(5.08)\end{array}$ & $\begin{array}{l}0.716^{* * *} \\
(4.92)\end{array}$ & $\begin{array}{l}0.736^{* * *} \\
(4.83)\end{array}$ \\
\hline 4G spectrum $(\mathrm{MHz})$ & $\begin{array}{l}0.00502 * * * \\
(3.75)\end{array}$ & $\begin{array}{l}0.000933 \\
(0.34)\end{array}$ & $\begin{array}{l}-0.00120 \\
(-0.31)\end{array}$ & $\begin{array}{l}0.00544 * * * \\
(3.77)\end{array}$ & $\begin{array}{l}0.00570^{* * *} \\
(3.89)\end{array}$ & $\begin{array}{l}0.00620^{* * * *} \\
(3.87)\end{array}$ \\
\hline \multicolumn{7}{|l|}{ Operator FE: } \\
\hline $\mathrm{TMCZ}$ & $\begin{array}{l}-0.0407^{* * *} \\
(-3.60)\end{array}$ & $\begin{array}{l}-0.0203 \\
(-1.20)\end{array}$ & $\begin{array}{l}0.000496 \\
(0.02)\end{array}$ & $\begin{array}{l}-0.0437 * * * \\
(-3.79)\end{array}$ & $\begin{array}{l}-0.0469 * * * \\
(-4.18)\end{array}$ & $\begin{array}{l}-0.0405^{* * *} \\
(-3.08)\end{array}$ \\
\hline Vodafone & $\begin{array}{l}-0.146^{*} \\
(-1.71)\end{array}$ & $\begin{array}{l}-0.0563 \\
(-0.53)\end{array}$ & $\begin{array}{l}0.0142 \\
(0.11)\end{array}$ & $\begin{array}{l}-0.162 * \\
(-1.88)\end{array}$ & $\begin{array}{l}-0.176^{* *} \\
(-2.04)\end{array}$ & $\begin{array}{l}-0.178 * * \\
(-2.12)\end{array}$ \\
\hline \multicolumn{7}{|l|}{ Year fixed effects: } \\
\hline 2013 & $\begin{array}{l}0.0616 \\
(1.23)\end{array}$ & $\begin{array}{l}0.0463 \\
(0.81)\end{array}$ & $\begin{array}{l}0.145 \\
(1.37)\end{array}$ & $\begin{array}{l}0.0508 \\
(1.10)\end{array}$ & $\begin{array}{l}0.0309 \\
(0.69)\end{array}$ & $\begin{array}{l}0.121 \\
(1.18)\end{array}$ \\
\hline 2014 & $\begin{array}{l}0.0304 \\
(0.43)\end{array}$ & $\begin{array}{l}0.0555 \\
(0.70)\end{array}$ & $\begin{array}{l}0.235 \\
(1.34)\end{array}$ & $\begin{array}{l}0.00835 \\
(0.13)\end{array}$ & $\begin{array}{l}-0.0260 \\
(-0.41)\end{array}$ & $\begin{array}{l}0.108 \\
(0.70)\end{array}$ \\
\hline 2015 & $\begin{array}{l}-0.0268 \\
(-0.37)\end{array}$ & $\begin{array}{l}0.0605 \\
(0.65)\end{array}$ & $\begin{array}{l}0.277 \\
(1.33)\end{array}$ & $\begin{array}{l}-0.0557 \\
(-0.84)\end{array}$ & $\begin{array}{l}-0.0949 \\
(-1.45)\end{array}$ & $\begin{array}{l}0.0355 \\
(0.23)\end{array}$ \\
\hline 2016 & $\begin{array}{l}-0.0454 \\
(-0.59)\end{array}$ & $\begin{array}{l}0.0983 \\
(0.84)\end{array}$ & $\begin{array}{l}0.350 \\
(1.42)\end{array}$ & $\begin{array}{l}-0.0808 \\
(-1.13)\end{array}$ & $\begin{array}{l}-0.125^{*} \\
(-1.77)\end{array}$ & $\begin{array}{l}0.00357 \\
(0.02)\end{array}$ \\
\hline 2017 & $\begin{array}{l}-0.0571 \\
(-0.67)\end{array}$ & $\begin{array}{l}0.168 \\
(1.08)\end{array}$ & $\begin{array}{l}0.464 \\
(1.54)\end{array}$ & $\begin{array}{l}-0.101 \\
(-1.25)\end{array}$ & $\begin{array}{l}-0.151^{*} \\
(-1.88)\end{array}$ & $\begin{array}{l}-0.0312 \\
(-0.21)\end{array}$ \\
\hline Constant & $\begin{array}{l}1.288^{* * * *} \\
(5.66)\end{array}$ & $\begin{array}{l}1.551^{* * *} \\
(5.57)\end{array}$ & $\begin{array}{l}1.330^{* * * *} \\
(3.45)\end{array}$ & $\begin{array}{l}1.294 * * * \\
(5.82)\end{array}$ & $\begin{array}{l}1.342 * * * \\
(5.95)\end{array}$ & $\begin{array}{l}0.992 * * \\
(2.53)\end{array}$ \\
\hline Observations & 72 & 72 & 72 & 72 & 72 & 72 \\
\hline Adj. $R^{2}$ & 0.991 & 0.989 & 0.983 & 0.991 & 0.990 & 0.990 \\
\hline Over-identification test (p-value) & 0.0553 & 0.0569 & 0.138 & 0.0790 & 0.0207 & 0.00405 \\
\hline Elasticities: & & & & & & \\
\hline Own price elasticity & -1.017 & -2.515 & -76.19 & -0.977 & -1.023 & -0.380 \\
\hline Cross price elasticity & 0.466 & 1.194 & 37.58 & 0.444 & 0.461 & 0.172 \\
\hline Instruments: & & & & & & \\
\hline Lags of own price & Yes & Yes & No & Yes & Yes & No \\
\hline Lags of own (within group) market share & Yes & Yes & Yes & Yes & Yes & Yes \\
\hline Lag of own download speed & Yes & No & No & Yes & Yes & Yes \\
\hline Lags of prices of operators in Slovakia & Yes & Yes & Yes & Yes & No & No \\
\hline Lags of download speeds of competitors & No & No & No & Yes & Yes & Yes \\
\hline
\end{tabular}

Notes: $t$-values in parentheses. ${ }^{*} p<0.1,{ }^{* *} p<0.05,{ }^{* *} p<0.01$. In subtable (B), the lags of download speeds of competitors have been included as instruments. Operator fixed effects are relative to $\mathrm{O} 2$, the omitted MNO.

Source: Authors' calculation.

\subsubsection{Data traffic as proxy for $4 \mathrm{G}$ coverage}

To be able to consider the complete temporal coverage of the Ookla dataset, data traffic has been used as a proxy for $4 \mathrm{G}$ coverage (or "data availability coverage"). Since this variable is reported at the industry level, however, an interaction with the market share of each operator for data revenue at the retail level has been included. This market share data is also available in the AM dataset.

Results are displayed in Table 7-5. The relevant coefficients display the expected signs and significance levels. The only exception is specification (6), in which $\sigma$ becomes higher than 1 . Finally, note that in 
these specifications the null-hypothesis of the validity of the instruments is rejected (see the p-values of the over-identification tests)

Table 7-5: Demand estimates with data traffic as proxy for 4G coverage

\begin{tabular}{|c|c|c|c|c|c|c|}
\hline \multirow[b]{4}{*}{ In(Market share) } & (1) & (2) & (3) & (4) & (5) & (6) \\
\hline & \multicolumn{6}{|c|}{ Change in instruments } \\
\hline & \multicolumn{3}{|c|}{ (A) } & \multicolumn{3}{|c|}{ (B) } \\
\hline & Base & $\begin{array}{c}\text { No own } \\
\text { download } \\
\text { speed }\end{array}$ & No own price & Base & $\begin{array}{l}\text { No prices in } \\
\text { Slovakia }\end{array}$ & No own price \\
\hline Price $(-\alpha)$ & $\begin{array}{l}-0.0144 * * * \\
(-18.79)\end{array}$ & $\begin{array}{l}-0.0140^{* * *} \\
(-15.34)\end{array}$ & $\begin{array}{l}-0.0140^{* * *} \\
(-15.23)\end{array}$ & $\begin{array}{l}-0.0143^{* * *} \\
(-19.22)\end{array}$ & $\begin{array}{l}-0.0143 * * * \\
(-19.42)\end{array}$ & $\begin{array}{l}-0.0217 * * * \\
(-7.93)\end{array}$ \\
\hline Avg. download speed ( $\beta$ ) & $\begin{array}{l}0.00641^{* * *} \\
(7.62)\end{array}$ & $\begin{array}{l}0.00693 * * * \\
(6.13)\end{array}$ & $\begin{array}{l}0.00688 * * * \\
(6.09)\end{array}$ & $\begin{array}{l}0.00654 * * * \\
(7.77)\end{array}$ & $\begin{array}{l}0.00653 * * * \\
(7.95)\end{array}$ & $\begin{array}{l}0.000827 \\
(0.35)\end{array}$ \\
\hline Market share within group $(\sigma)$ & $\begin{array}{l}0.794 * * * \\
(7.08)\end{array}$ & $\begin{array}{l}0.767 * * * \\
(6.31)\end{array}$ & $\begin{array}{l}0.772 * * * \\
(6.42)\end{array}$ & $\begin{array}{l}0.781 * * * \\
(7.05)\end{array}$ & $\begin{array}{l}0.772 * * * \\
(7.03)\end{array}$ & $\begin{array}{l}1.144 * * * \\
(4.92)\end{array}$ \\
\hline $\begin{array}{l}\text { Data traffic * Market share (in retail } \\
\text { data) }\end{array}$ & $\begin{array}{l}0.00407^{* * *} \\
(4.65)\end{array}$ & $\begin{array}{l}0.00358 * * * \\
(3.09)\end{array}$ & $\begin{array}{l}0.00364 * * * \\
(3.13)\end{array}$ & $\begin{array}{l}0.00395 * * * \\
(4.51)\end{array}$ & $\begin{array}{l}0.00395 * * * \\
(4.59)\end{array}$ & $\begin{array}{l}0.00861^{* * *} \\
(4.55)\end{array}$ \\
\hline \multicolumn{7}{|l|}{ Operator FE: } \\
\hline $\mathrm{TMCZ}$ & $\begin{array}{l}-0.0368^{* * *} \\
(-4.28)\end{array}$ & $\begin{array}{l}-0.0366^{* * *} \\
(-4.24)\end{array}$ & $\begin{array}{l}-0.0366^{* * *} \\
(-4.25)\end{array}$ & $\begin{array}{l}-0.0366^{* * *} \\
(-4.25)\end{array}$ & $\begin{array}{l}-0.0363 * * * \\
(-4.23)\end{array}$ & $\begin{array}{l}-0.0443^{* * *} \\
(-3.26)\end{array}$ \\
\hline Vodafone & $\begin{array}{l}-0.108 * \\
(-1.67)\end{array}$ & $\begin{array}{l}-0.127^{*} \\
(-1.76)\end{array}$ & $\begin{array}{l}-0.124 * \\
(-1.74)\end{array}$ & $\begin{array}{l}-0.116^{*} \\
(-1.81)\end{array}$ & $\begin{array}{l}-0.121 * \\
(-1.91)\end{array}$ & $\begin{array}{l}0.133 \\
(0.95)\end{array}$ \\
\hline Constant & $\begin{array}{l}1.549 * * * \\
(12.15)\end{array}$ & $\begin{array}{l}1.506^{* * *} \\
(10.41)\end{array}$ & $\begin{array}{l}1.511 * * * \\
(10.54)\end{array}$ & $\begin{array}{l}1.532 * * * \\
(12.24)\end{array}$ & $\begin{array}{l}1.524 * * * \\
(12.31)\end{array}$ & $\begin{array}{l}2.192^{* * * *} \\
(6.88)\end{array}$ \\
\hline Observations & 96 & 96 & 96 & 96 & 96 & 96 \\
\hline Adj. $R^{2}$ & 0.989 & 0.989 & 0.989 & 0.989 & 0.989 & 0.976 \\
\hline Over-identification test (p-value) & 0.00195 & 0.00306 & 0.000748 & 0.00113 & 0.000491 & 0.480 \\
\hline Elasticities: & & & & & & \\
\hline Own price elasticity & -1.675 & -1.445 & -1.476 & -1.565 & -1.509 & 3.487 \\
\hline Cross price elasticity & 0.774 & 0.662 & 0.677 & 0.720 & 0.692 & -1.800 \\
\hline Instruments: & & & & & & \\
\hline Lags of own price & Yes & Yes & No & Yes & Yes & No \\
\hline Lags of own (within group) market share & Yes & Yes & Yes & Yes & Yes & Yes \\
\hline Lag of own download speed & Yes & No & No & Yes & Yes & Yes \\
\hline Lags of prices of operators in Slovakia & Yes & Yes & Yes & Yes & No & No \\
\hline Lags of download speeds of competitors & No & No & No & Yes & Yes & Yes \\
\hline
\end{tabular}

Notes: $\mathrm{t}$-values in parentheses. ${ }^{*} \mathrm{p}<0.1,{ }^{* *} \mathrm{p}<0.05,{ }^{* * *} \mathrm{p}<0.01$. In subtable (B), the lags of download speeds of competitors have been included as instruments. Operator fixed effects are relative to $\mathrm{O} 2$, the omitted MNO.

Source: Authors' calculation.

\subsubsection{Simple OLS estimates}

To illustrate that the obtained results are not driven by the choice of instruments, Table 7-6 displays the results of estimating the baseline specification with OLS. It can be observed that all variables have the expected signs and significance levels. 


\begin{tabular}{|c|c|c|}
\hline $\ln ($ Market share) & $\begin{array}{c}\text { (1) } \\
\text { Base }\end{array}$ & $\begin{array}{c}\text { (2) } \\
+ \text { Data traffic } \\
\text { interaction }\end{array}$ \\
\hline Price $(-\alpha)$ & $\begin{array}{l}-0.0129^{* * *} \\
(-12.81)\end{array}$ & $\begin{array}{l}-0.0146^{* * *} \\
(-19.91)\end{array}$ \\
\hline Avg. download speed $(\beta)$ & $\begin{array}{l}0.00824^{* * *} \\
(11.20)\end{array}$ & $\begin{array}{l}0.00616^{* * *} \\
(7.40)\end{array}$ \\
\hline Market share within group $(\sigma)$ & $\begin{array}{l}0.876^{* * *} \\
(5.36)\end{array}$ & $\begin{array}{l}0.858^{* * * *} \\
(7.48)\end{array}$ \\
\hline 4G spectrum $(\mathrm{MHz})$ & $\begin{array}{l}0.00273 * * * \\
(3.95)\end{array}$ & \\
\hline Data traffic $*$ Market share (in retail data) & & $\begin{array}{l}0.00434^{* * *} \\
(4.86)\end{array}$ \\
\hline \multicolumn{3}{|l|}{ Operator FE: } \\
\hline TMCZ & $\begin{array}{l}-0.0334^{* * * *} \\
(-2.92)\end{array}$ & $\begin{array}{l}-0.0387^{* * *} \\
(-4.34)\end{array}$ \\
\hline Vodafone & $\begin{array}{l}-0.0731 \\
(-0.79)\end{array}$ & $\begin{array}{l}-0.0710 \\
(-1.08)\end{array}$ \\
\hline Constant & $\begin{array}{l}1.551^{* * *} \\
(8.47)\end{array}$ & $\begin{array}{l}1.617 * * * \\
(12.74)\end{array}$ \\
\hline Observations & 72 & 99 \\
\hline Adj. $R^{2}$ & 0.988 & 0.989 \\
\hline Elasticities: & & \\
\hline Own price elasticity & -2.474 & -2.444 \\
\hline Cross price elasticity & 1.174 & 1.153 \\
\hline
\end{tabular}

Notes: $\mathrm{t}$-values in parentheses. ${ }^{*} \mathrm{p}<0.1,{ }^{* *} \mathrm{p}<0.05,{ }^{* * *} \mathrm{p}<0.01$. Operator fixed effects are relative to 02, the omitted MNO.

Source: Authors' calculation.

\subsection{Robustness checks of the cost estimation}

Table 7-7, Table 7-8 and Table 7-9 display the results of the baseline cost specification, including trends (specification 1), year fixed effects (specification 2) and period fixed effects (specification 3 ), for the marginal cost per user, the quality cost parameter obtained under the geo-split equilibrium and the quality cost parameter obtained under the JV equilibrium, respectively. Moreover, as a robustness check, each table contains the estimation of a cost equation in which the impact of the NSA on costs is captured by an operator-specific dummy that takes the value of 1 for every period after Q1-2014 and takes the value of zero otherwise (DiD specification). These robustness checks are presented including trends (specification 4), year fixed effects (specification 5) and period fixed effects (specification 6).

In Table 7-7, the coefficients associated with the deployment of $4 \mathrm{G}$ sites (shared and non-shared) remain almost unchanged across specifications. In addition, in specifications (4) to (6) the operatorspecific coefficients associated with the Parties are negative, confirming the fact that the NSA generates cost efficiencies. Note, however, that only the coefficient associated with TMCZ is 
significant in this case. As shown in the table, these latter results are robust to the inclusion of either, trends, year or period fixed effects.

Table 7-7: Cost equation (marginal cost per user), robustness checks

\begin{tabular}{|c|c|c|c|c|c|c|}
\hline Marginal cost per user & $\begin{array}{c}(1) \\
\text { Base - Sites }\end{array}$ & $\begin{array}{c}(2) \\
+ \text { Trends, no } \\
\text { year FE }\end{array}$ & $\begin{array}{c}\text { (3) } \\
\text { Period fixed } \\
\text { effects }\end{array}$ & $\begin{array}{c}\text { (4) } \\
\text { Base - DiD }\end{array}$ & $\begin{array}{c}(5) \\
+ \text { Trends, no } \\
\text { year FE }\end{array}$ & $\begin{array}{c}\text { (6) } \\
\text { Period fixed } \\
\text { effects }\end{array}$ \\
\hline Shared $4 \mathrm{G}$ sites & $\begin{array}{l}1.136^{* * * *} \\
(3.66)\end{array}$ & $\begin{array}{l}1.116^{* * * *} \\
(4.60)\end{array}$ & $\begin{array}{l}1.136^{* * *} \\
(4.27)\end{array}$ & & & \\
\hline Non-shared $4 \mathrm{G}$ sites & $\begin{array}{l}2.307 * * * \\
(4.98)\end{array}$ & $\begin{array}{l}2.210^{* * *} \\
(7.00)\end{array}$ & $\begin{array}{l}2.307^{* * *} \\
(6.01)\end{array}$ & & & \\
\hline NSA (before-after 2014) & & & & $\begin{array}{l}0.752 \\
(0.89)\end{array}$ & $\begin{array}{l}-1.655^{*} \\
(-1.91)\end{array}$ & $\begin{array}{l}-116.0^{* * * *} \\
(-4.37)\end{array}$ \\
\hline \multicolumn{7}{|l|}{ Treatment effect: } \\
\hline $\mathrm{NSA} * \mathrm{O} 2$ & & & & $\begin{array}{l}1.103 \\
(-1.18)\end{array}$ & $\begin{array}{l}-1.103 \\
(-1.39)\end{array}$ & $\begin{array}{l}-1.103 \\
(-1.46)\end{array}$ \\
\hline $\mathrm{NSA} * \mathrm{TMCZ}$ & & & & $\begin{array}{l}-1.959 * * \\
(-2.23)\end{array}$ & $\begin{array}{l}-1.959 * * * \\
(-2.66)\end{array}$ & $\begin{array}{l}-1.959 * * \\
(-2.63)\end{array}$ \\
\hline Trend & & $\begin{array}{l}-2.389^{* * *} \\
(-9.09)\end{array}$ & & & $\begin{array}{l}-0.834 * * * \\
(-3.72)\end{array}$ & \\
\hline Trend $^{2}$ & & $\begin{array}{l}0.0627 * * * \\
(10.27)\end{array}$ & & & $\begin{array}{l}0.0309^{* * *} \\
(4.83)\end{array}$ & \\
\hline MTR & $\begin{array}{l}8.175^{* * * *} \\
(6.64)\end{array}$ & $\begin{array}{l}4.990^{* * * *} \\
(4.58)\end{array}$ & $\begin{array}{l}22.070^{* * * *} \\
(9.65)\end{array}$ & $\begin{array}{c}7.317^{* * *} \\
(5.13)\end{array}$ & $\begin{array}{l}3.151 * * * \\
(10.22)\end{array}$ & $\begin{array}{c}-29.970^{* * * *} \\
(-3.79)\end{array}$ \\
\hline \multicolumn{7}{|l|}{ Operator FE: } \\
\hline $\mathrm{TMCZ}$ & $\begin{array}{l}-2.023 * * * \\
(-6.32)\end{array}$ & $\begin{array}{l}-1.999 * * * \\
(-8.85)\end{array}$ & $\begin{array}{l}-2.023 * * * \\
(-8.43)\end{array}$ & $\begin{array}{l}-0.673 \\
(-0.89)\end{array}$ & $\begin{array}{l}-0.673 \\
(-0.93)\end{array}$ & $\begin{array}{l}-0.673 \\
(-1.21)\end{array}$ \\
\hline Vodafone & $\begin{array}{l}3.238^{* * *} \\
(4.61)\end{array}$ & $\begin{array}{l}3.426^{* * *} \\
(6.04)\end{array}$ & $\begin{array}{l}3.238^{* * *} \\
(6.04)\end{array}$ & $\begin{array}{l}5.700^{* * *} \\
(6.50)\end{array}$ & $\begin{array}{l}5.700^{* * *} \\
(7.98)\end{array}$ & $\begin{array}{l}5.700^{* * *} \\
(8.07)\end{array}$ \\
\hline Constant & $\begin{array}{l}3.487 * \\
(1.90)\end{array}$ & $\begin{array}{l}19.490^{* * * *} \\
(7.15)\end{array}$ & $\begin{array}{l}-18.350 * * * \\
(-5.00)\end{array}$ & $\begin{array}{l}4.230^{* *} \\
(2.33)\end{array}$ & $\begin{array}{l}13.890^{* * * *} \\
(7.51)\end{array}$ & $\begin{array}{l}154.2 * * * \\
(4.57)\end{array}$ \\
\hline Observations & 60 & 60 & 60 & 72 & 72 & 72 \\
\hline Adj. $R^{2}$ & 0.960 & 0.962 & 0.971 & 0.969 & 0.975 & 0.978 \\
\hline Quarter fixed effeccs & Yes & Yes & Yes & Yes & Yes & Yes \\
\hline Year fixed effects & Yes & No & No & Yes & No & No \\
\hline Period fixed effects & No & No & Yes & No & No & Yes \\
\hline
\end{tabular}

Notes: t-values in parentheses. ${ }^{*} \mathrm{p}<0.1,{ }^{* *} \mathrm{p}<0.05,{ }^{* * *} \mathrm{p}<0.01$. Operator fixed effects are relative to 02 , the omitted MNO.

Source: Authors' calculation.

Table 7-8 contains the results associated with the quality cost parameter recovered under the geosplit equilibrium. In this case, both the shared and non-shared sites coefficients are lower in the specification including trends. Note, however, that the difference between both coefficients (i.e. the measure of cost efficiencies generated by the NSA) is similar across specifications. In specifications (4) to (6) the operator-specific coefficients associated with the NSA parties are both negative and significant, confirming the fact that the NSA generates cost efficiencies. 
Table 7-8: Cost equation (quality cost parameter), robustness checks

\begin{tabular}{|c|c|c|c|c|c|c|}
\hline $\begin{array}{l}\text { Quality cost parameter } \\
\text { (Competitive) }\end{array}$ & $\begin{array}{c}\text { (1) } \\
\text { Base - Sites }\end{array}$ & $\begin{array}{c}\text { (2) } \\
+\begin{array}{c}\text { Trends, no } \\
\text { year FE }\end{array}\end{array}$ & $\begin{array}{l}\text { (3) } \\
\text { Period fixed } \\
\text { effects }\end{array}$ & $\begin{array}{c}\text { (4) } \\
\text { Base - DiD }\end{array}$ & $\begin{array}{c}\text { (5) } \\
+\begin{array}{c}\text { Trends, no } \\
\text { year FE }\end{array}\end{array}$ & $\begin{array}{c}\text { (6) } \\
\text { Period fixed } \\
\text { effects }\end{array}$ \\
\hline Shared $4 \mathrm{G}$ sites & $\begin{array}{l}0.0379^{* * *} \\
(2.18)\end{array}$ & $\begin{array}{l}0.00920 \\
(0.83)\end{array}$ & $\begin{array}{l}0.0379 * * \\
(2.08)\end{array}$ & & & \\
\hline Non-shared 4G sites & $\begin{array}{l}0.107 * * * \\
(3.67)\end{array}$ & $\begin{array}{l}0.0641 * * * \\
(3.14)\end{array}$ & $\begin{array}{l}0.107 * * * \\
(3.36)\end{array}$ & & & \\
\hline NSA (before-after 2014) & & & & $\begin{array}{l}-0.0500^{*} \\
(-1.81)\end{array}$ & $\begin{array}{l}0.0459^{* *} \\
(2.02)\end{array}$ & $\begin{array}{l}-1.665 \\
(-0.77)\end{array}$ \\
\hline \multicolumn{7}{|l|}{ Treatment effect: } \\
\hline $\mathrm{NSA} * \mathrm{O} 2$ & & & & $\begin{array}{l}-0.338^{* * *} \\
(-14.48)\end{array}$ & $\begin{array}{l}-0.338^{* * *} \\
(-21.19)\end{array}$ & $\begin{array}{l}-0.338^{* * *} \\
(-18.13)\end{array}$ \\
\hline $\mathrm{NSA} * \mathrm{TMCZ}$ & & & & $\begin{array}{l}-0.0840 * * * \\
(-3.50)\end{array}$ & $\begin{array}{l}-0.0840 * * * \\
(-4.52)\end{array}$ & $\begin{array}{l}-0.0840 * * * \\
(-4.33)\end{array}$ \\
\hline Trend & & $\begin{array}{l}-0.0798^{* * * *} \\
(-3.96)\end{array}$ & & & $\begin{array}{l}-0.0327 * * * \\
(-6.30)\end{array}$ & \\
\hline Trend-squared & & $\begin{array}{l}0.00194 * * * \\
(3.94)\end{array}$ & & & $\begin{array}{l}0.00080 * * * \\
(5.54)\end{array}$ & \\
\hline MTR & $\begin{array}{l}0.172 * \\
(1.83)\end{array}$ & $\begin{array}{l}0.0586 \\
(0.56)\end{array}$ & $\begin{array}{l}0.978^{* * * *} \\
(4.82)\end{array}$ & $\begin{array}{l}0.172 * * * \\
(3.77)\end{array}$ & $\begin{array}{l}0.0138^{* *} \\
(2.14)\end{array}$ & $\begin{array}{l}-0.405 \\
(-0.63)\end{array}$ \\
\hline Operator FE: & & & & & & \\
\hline TMCZ & $\begin{array}{l}-0.0883^{* * * *} \\
(-3.95)\end{array}$ & $\begin{array}{l}-0.0771 * * * \\
(-3.56)\end{array}$ & $\begin{array}{l}-0.0883^{* * * *} \\
(-3.49)\end{array}$ & $\begin{array}{l}-0.264 * * * \\
(-14.10)\end{array}$ & $\begin{array}{l}-0.264 * * * \\
(-13.64)\end{array}$ & $\begin{array}{l}-0.264 * * * \\
(-21.30)\end{array}$ \\
\hline Vodafone & $\begin{array}{l}-0.304 * * * \\
(-6.35)\end{array}$ & $\begin{array}{l}-0.267 * * * \\
(-5.59)\end{array}$ & $\begin{array}{l}-0.304^{* * *} \\
(-5.59)\end{array}$ & $\begin{array}{l}-0.403^{* * *} \\
(-18.79)\end{array}$ & $\begin{array}{l}-0.403 * * * \\
(-28.79)\end{array}$ & $\begin{array}{l}-0.403 * * * \\
(-23.81)\end{array}$ \\
\hline Constant & $\begin{array}{l}0.189 \\
(1.39)\end{array}$ & $\begin{array}{l}0.752^{* * * *} \\
(3.08)\end{array}$ & $\begin{array}{l}-1.104 * * * \\
(-3.74)\end{array}$ & $\begin{array}{l}0.310^{* * *} \\
(4.61)\end{array}$ & $\begin{array}{l}0.697 * * * \\
(18.79)\end{array}$ & $\begin{array}{l}2.458 \\
(0.89)\end{array}$ \\
\hline Observations & 60 & 60 & 60 & 72 & 72 & 72 \\
\hline Adj. $\mathrm{R}^{2}$ & 0.830 & 0.814 & 0.792 & 0.972 & 0.981 & 0.982 \\
\hline Year fixed effects & Yes & No & No & Yes & No & No \\
\hline Period fixed effects & No & No & Yes & No & No & Yes \\
\hline
\end{tabular}

Notes: t-values in parentheses. ${ }^{*} \mathrm{p}<0.1, * * \mathrm{p}<0.05, * * * \mathrm{p}<0.01$. Because of the timing in the deployment of $4 \mathrm{G}$ sites, specifications 1 to 3 cover the period from Q1-2013 to Q4-2017 (60 observations), while specifications 4 to 6 cover the whole estimation period from Q1-2012 to Q4-2017 (72 observations). Operator fixed effects are relative to O2, the omitted MNO. Source: Authors' calculation.

Table 7-9 presents the results associated with the quality cost parameter recovered under the JV equilibrium. As in the previous case, both the shared and non-shared sites coefficients are lower in the specification that includes trends. The difference between both coefficients (i.e. the measure of cost efficiencies generated by the NSA) is, however, similar across specifications. Finally, in specifications (4) to (6) the operator-specific coefficients associated with the NSA parties are both negative and significant, confirming the fact that the NSA generates cost efficiencies. 
Table 7-9: Cost equation (quality cost parameter JV model), robustness checks

\begin{tabular}{|c|c|c|c|c|c|c|}
\hline $\begin{array}{l}\text { Quality cost parameter } \\
\text { (Hybrid) }\end{array}$ & $\begin{array}{c}\text { (1) } \\
\text { Base - Sites }\end{array}$ & $\begin{array}{c}\text { (2) } \\
+ \text { Trends, no } \\
\text { year } \mathrm{FE}\end{array}$ & $\begin{array}{l}\text { (3) } \\
\text { Period fixed } \\
\text { effects }\end{array}$ & $\begin{array}{c}(4) \\
\text { Base - DiD }\end{array}$ & $\begin{array}{c}\text { (5) } \\
+ \text { Trends, no } \\
\quad \text { year } \mathrm{FE}\end{array}$ & $\begin{array}{l}\text { (6) } \\
\text { Period fixed } \\
\text { effects }\end{array}$ \\
\hline Shared $4 \mathrm{G}$ sites & $\begin{array}{l}0.0714^{* * *} \\
(3.94)\end{array}$ & $\begin{array}{l}0.0181 \\
(1.42)\end{array}$ & $\begin{array}{l}0.0714^{* * *} \\
(3.45)\end{array}$ & & & \\
\hline Non-shared 4G sites & $\begin{array}{l}0.157^{* * *} \\
(5.16)\end{array}$ & $\begin{array}{l}0.0785^{* * *} \\
(3.20)\end{array}$ & $\begin{array}{l}0.157 * * * \\
(4.52)\end{array}$ & & & \\
\hline \multicolumn{7}{|l|}{ Treatment effect } \\
\hline $\mathrm{NSA} * \mathrm{O} 2$ & & & & $\begin{array}{l}-0.407 * * * \\
(-18.79)\end{array}$ & $\begin{array}{l}-0.407 * * * \\
(-26.71)\end{array}$ & $\begin{array}{l}-0.407 * * * \\
(-23.89)\end{array}$ \\
\hline NSA $*$ TMCZ & & & & $\begin{array}{l}-0.144 * * * \\
(-6.07)\end{array}$ & $\begin{array}{l}-0.144^{* * *} \\
(-7.43)\end{array}$ & $\begin{array}{l}-0.144 * * * \\
(-7.64)\end{array}$ \\
\hline NSA (before-after 2014) & & & & $\begin{array}{l}-0.0349 \\
(-1.29)\end{array}$ & $\begin{array}{l}0.0112 \\
(0.59)\end{array}$ & $\begin{array}{l}-0.930^{*} \\
(-1.68)\end{array}$ \\
\hline Trend & & $\begin{array}{l}-0.0992 * * * \\
(-4.02)\end{array}$ & & & $\begin{array}{l}-0.0270^{* * *} \\
(-6.35)\end{array}$ & \\
\hline Trend $^{2}$ & & $\begin{array}{l}0.00248^{* * *} \\
(4.12)\end{array}$ & & & $\begin{array}{l}0.00072 * * * \\
(5.74)\end{array}$ & \\
\hline MTR & $\begin{array}{l}0.170^{*} \\
(1.80)\end{array}$ & $\begin{array}{l}0.0767 \\
(0.60)\end{array}$ & $\begin{array}{l}1.316^{* * *} \\
(5.98)\end{array}$ & $\begin{array}{l}0.170 * * * \\
(3.74)\end{array}$ & $\begin{array}{l}0.0208^{* * *} \\
(3.57)\end{array}$ & $\begin{array}{l}-0.190 \\
(-1.15)\end{array}$ \\
\hline Operator FE: & & & & & & \\
\hline TMCZ & $\begin{array}{l}-0.0937 * * * \\
(-4.07)\end{array}$ & $\begin{array}{l}-0.0732 * * * \\
(-2.75)\end{array}$ & $\begin{array}{l}-0.0937^{* * *} \\
(-3.55)\end{array}$ & $\begin{array}{l}-0.264 * * * \\
(-14.05)\end{array}$ & $\begin{array}{l}-0.264 * * * \\
(-12.91)\end{array}$ & $\begin{array}{l}-0.264 * * * \\
(-21.30)\end{array}$ \\
\hline Vodafone & $\begin{array}{l}-0.293 * * * \\
(-5.84)\end{array}$ & $\begin{array}{l}-0.225^{* * *} \\
(-3.72)\end{array}$ & $\begin{array}{l}-0.293^{* * *} \\
(-5.11)\end{array}$ & $\begin{array}{l}-0.403^{* * *} \\
(-18.84)\end{array}$ & $\begin{array}{l}-0.403^{* * *} \\
(-27.14)\end{array}$ & $\begin{array}{l}-0.403 * * * \\
(-23.81)\end{array}$ \\
\hline Constant & $\begin{array}{l}0.175 \\
(1.30)\end{array}$ & $\begin{array}{l}0.796 * * \\
(2.60)\end{array}$ & $\begin{array}{l}-1.670^{* * *} \\
(-5.14)\end{array}$ & $\begin{array}{l}0.312^{* * *} \\
(4.65)\end{array}$ & $\begin{array}{l}0.653 * * * \\
(20.64)\end{array}$ & $\begin{array}{l}1.541^{* *} \\
(2.18)\end{array}$ \\
\hline Observations & 60 & 60 & 60 & 72 & 72 & 72 \\
\hline Adj. $R^{2}$ & 0.843 & 0.743 & 0.795 & 0.983 & 0.986 & 0.990 \\
\hline Year fixed effects & Yes & No & No & Yes & No & No \\
\hline Period fixed effects & No & No & Yes & No & No & Yes \\
\hline
\end{tabular}

Notes: t-values in parentheses. ${ }^{*} \mathrm{p}<0.1,{ }^{* *} \mathrm{p}<0.05,{ }^{* * *} \mathrm{p}<0.01$. Because of the timing in the deployment of $4 \mathrm{G}$ sites, specifications 1 to 3 cover the period from Q1-2013 to Q4-2017 (60 observations), while specifications 4 to 6 cover the whole estimation period from Q1-2012 to Q4-2017 (72 observations). Operator fixed effects are relative to O2, the omitted MNO. Source: Authors' calculation.

\subsection{Robustness checks relating to the geo-split equilibrium}

This section shows that the results presented in Section 5.3.3 do not depend on the assumption that counterfactual costs of quality $\tilde{k}_{i t}^{G S}$ for all MNOs are increased by $20 \%$. We keep increasing marginal costs of quantity for Vodafone by $33 \%$ but vary the exogenous increase in counterfactual quality costs for all firms. The result of this exercise is summarized in Table 7-10 below and shows that regardless of the magnitude of the considered exogenous cost increase, the NSA results in lower prices, higher network quality and higher consumer surplus. 
Table 7-10: Sensitivity analysis geo-split equilibrium

\begin{tabular}{|c|c|c|c|c|c|}
\hline \multirow{2}{*}{\multicolumn{2}{|c|}{$\begin{array}{l}\text { Exogenous increase of the } \\
\text { quality cost parameter }\end{array}$}} & & \multicolumn{3}{|c|}{ Operator } \\
\hline & & & TMCZ & $\mathrm{O} 2$ & Vodafone \\
\hline \multirow{7}{*}{ Price } & & \multirow{7}{*}{$\%$} & & \% - -- & -------- \\
\hline & 5 & & 12.9 & 12.6 & 14.7 \\
\hline & 10 & & 12.1 & 12.1 & 15.7 \\
\hline & 15 & & 13.1 & 13.1 & 14.6 \\
\hline & 20 & & 14.8 & 14.6 & 12.5 \\
\hline & 25 & & 14.7 & 14.6 & 12.5 \\
\hline & 30 & & 14.6 & 14.5 & 12.6 \\
\hline \multirow{6}{*}{ Download speed } & 5 & \multirow{6}{*}{$\%$} & -4.0 & -3.3 & -13.5 \\
\hline & 10 & & -10.6 & -9.6 & -10.3 \\
\hline & 15 & & -12.6 & -10.8 & -24.0 \\
\hline & 20 & & -11.3 & -9.8 & -44.3 \\
\hline & 25 & & -15.2 & -13.6 & -46.1 \\
\hline & 30 & & -18.8 & -17.1 & -47.8 \\
\hline \multirow{8}{*}{$\begin{array}{l}\text { Consumer } \\
\text { Surplus }\end{array}$} & & \multirow{8}{*}{$\%$} & \multicolumn{3}{|c|}{ Industry wide } \\
\hline & & & \multicolumn{2}{|r|}{$\%$} & $€ \mathrm{Mn}$ \\
\hline & 5 & & \multicolumn{2}{|r|}{-4.1} & -77.5 \\
\hline & 10 & & \multicolumn{2}{|r|}{-4.5} & -83.4 \\
\hline & 15 & & \multicolumn{2}{|r|}{-5.2} & -96.6 \\
\hline & 20 & & \multicolumn{2}{|r|}{-5.9} & -111.1 \\
\hline & 25 & & \multicolumn{2}{|r|}{-6.3} & -118.1 \\
\hline & 30 & & \multicolumn{2}{|r|}{-6.6} & -124.5 \\
\hline
\end{tabular}

Source: Authors' calculation.

\section{Conclusion}

We presented a structural model of demand and supply in telecommunication industries to estimate the effects of NSAs that are organized either in the form of a geo-splitting agreement or a joint venture. The methodological framework is general and can be applied by competition authorities and regulators around the globe to gauge the competitive effects of different network sharing agreements. We estimated the model in the Czech mobile telecommunications market to study the effects of the $2 \mathrm{G} / 3 \mathrm{G}$ and $4 \mathrm{G} / \mathrm{LTE}$ network sharing agreements between TMCZ and O2. We find that the NSAs had a positive impact on consumers by generating higher network quality and lower prices.

The application to the Czech Republic highlights that NSAs involving active sharing can be beneficial for consumers. As argued in Maier-Rigaud, Ivaldi \& Heller (2020), this finding has direct implications for competition policy. Overly restrictive scrutiny towards NSAs can result in adverse consequences on competitive outcomes and even absent any restrictive decisions, the threat of future scrutiny could prevent beneficial NSAs to be undertaken. We argue that no restrictions to network sharing based on potential anti-competitive effects should be implemented unless such effects have been demonstrated by a rigorous econometric assessment. By presenting a general framework for analyzing the competitive effects of NSAs, our paper offers a first step towards such an evidencebased approach. 


\section{References}

Andersen, L. R. (2016). Mobile network infrastructure sharing: A structured approach for evaluating and executing network sharing. Working Paper.

Arellano, M., \& Bover, O. (1995). Another Look at the Instrumental Variable Estimation of ErrorComponents Models. Journal of Econometrics, 68(1), 29-51.

Arrow, K. (1962). Economic Welfare and the Allocation of Resources for Invention. In U.-N. B. Research, The Rate and Direction of Inventive Activity: Economic and Social Factors (pp. 609626). Princeton: Princeton University Press.

BEREC - Body of European Regulators for Electronic Communications. (2018). BEREC Report on infrastructure sharing. Retrieved March 02, 2020, from https://berec.europa.eu/eng/document_register/subject_matter/berec/reports/8164-berecreport-on-infrastructure-sharing.

Berry, S. (1994). Estimating Discrete-Choice Models of Product Differentiation. The RAND Journal of Economics, 25(2), 242-262.

Berry, S., Levinsohn, J., \& Pakes, A. (1995). Automobile Prices in Market Equilibrium. Econometrica, 63(4), 841-890.

Blundell, R., \& Bond, S. (1998). Initial Conditions and Moment Restrictions in Dynamic Panel Data Models. Journal of Econometrics, 87(1), 115-143.

Bourreau, M., \& Jullien, B. (2018). Mergers, Investments and Demand Expansion. Economics Letters, 167 (June), 136-141.

Bourreau, M., Cambini, C., \& Hoernig, S. (2018). Cooperative Investment, Access and Uncertainty. International Journal of Industrial Organization, 56(1), 78-106.

Briglauer, W., Gugler, K., \& Haximusa, A. (2016). Facility- and Service-Based Competition and Investment in Fixed Broadband Networks: Lessons from a Decade of Access Regulations in the European Union Member States. Telecommunications Policy, 40(8), 729-742.

Crawford, G. S., Lee, R. S., Whinston, M. D., \& Yurukoglu, A. (2018). The Welfare Effects of Vertical Integration in Multichannel Television Markets. Econometrica, 86(3), 891-954.

d'Aspremont, C., \& Jacquemin, A. (1988). Cooperative and Noncooperative R\&D in Duopoly with Spillovers. American Economic Review 78(5), 1133-1137.

Denicolò, V., \& Polo, M. (2018). Duplicative Research, Mergers and Innovation. Economics Letters, 166, 56-59.

Fan, Y. (2013). Ownership Consolidation and Product Characteristics: A Study of the US Daily Newspaper Market. The American Economic Review, 103(5), 1598-1628.

Federico, G., Langus, G., \& Valletti, T. (2017). A Simple Model of Mergers and Innovation. Economics Letters, 157, 136-140. 
Gollier, C., \& Ivaldi, M. (2009). A Merger in the Insurance Industry: Much Easier to Measure Unilateral Effects than Expected. In B. Lyons, Cases in European Competition Policy: The Economic Analysis (pp. 293-311). Cambridge: Cambridge University Press.

Grajek, M., \& Röller, L.-H. (2012). Regulation and Investment in Network Industries: Evidence from European Telecoms. The Journal of Law \& Economics, 55(1), 189-216.

GSMA. (2012). Mobile Infrastructure Sharing. London: GSMA. Retrieved from https://www.gsma.com/publicpolicy/wp-content/uploads/2012/09/Mobile-Infrastructuresharing.pdf

GSMA. (2017). Assessing the impact of mobile consolidation on innovation and quality: An evaluation of the Hutchison/Orange merger in Austria. London: GSMA.

Ivaldi, M., \& Verboven, F. (2005). Quantifying the effects from horizontal mergers in European competition policy. International Journal of Industrial Organization, 669-691.

Jullien, B., \& Lefouili, Y. (2018). Horizontal Mergers and Innovation. Journal of Competition Law \& Economics, 14(3), 364-392.

Kennedy, P. E. (1981). Estimation with correctly interpreted dummy variables in semilogarithmic equations. American Economic Review, 71, 801.

Krämer, J., \& Vogelsang, L. (2016). Co-Investments and Tacit Collusion in Regulated Network Industries: Experimental Evidence. Review of Network Economics, 15(1), 35-61.

Maier-Rigaud, F. P., Ivaldi, M., \& Heller, C.-P. (2020). Cooperation among Competitors: Network sharing can increase Consumer Welfare. SSRN Working Paper: https://papers.ssrn.com/sol3/papers.cfm?abstract_id=3571354.

Motta, M., \& Tarantino, E. (2017). The Effect of Horizontal Mergers, When Firms Compete in Prices and Investments. Working Paper.

Nevo, A. (2000). Mergers with Differentiated Products: The Case of the Ready-to-Eat Cereal Industry. The RAND Journal of Economics, 31(3), 395-421.

Nitsche, R., \& Wiethaus, L. (2011). Access Regulation and Investment in Next Generation Networks -A Ranking of Regulatory Regimes. International Journal of Industrial Organization, 29(2), 263272.

Schumpeter, J. (1942). Capitalism, Socialism and Democracy.

Train, K. (2009). Discrete Choice Methods with Simulation (2 ed.). Cambridge: Cambridge University Press.

Villas-Boas, S. B. (2007). Vertical Relationships between Manufacturers and Retailers: Inference with Limited Data. The Review of Economic Studies, 74(2), 625-652. 